\title{
Self-exciting threshold binomial autoregressive processes
}

\author{
Tobias A. Möller ${ }^{1}$ • Maria Eduarda Silva ${ }^{2}$. \\ Christian H. Weiß ${ }^{1}$. Manuel G. Scotto ${ }^{3}$. \\ Isabel Pereira 4
}

Received: 5 May 2015 / Accepted: 29 November 2015 / Published online: 17 December 2015 (C) Springer-Verlag Berlin Heidelberg 2015

\begin{abstract}
We introduce a new class of integer-valued self-exciting threshold models, which is based on the binomial autoregressive model of order one as introduced by McKenzie (Water Resour Bull 21:645-650, 1985. doi:10.1111/j.1752-1688.1985. tb05379.x). Basic probabilistic and statistical properties of this class of models are discussed. Moreover, parameter estimation and forecasting are addressed. Finally, the performance of these models is illustrated through a simulation study and an empirical application to a set of measle cases in Germany.
\end{abstract}

Keywords Thinning operation - Threshold models · Binomial models · Count processes

\footnotetext{
$凶$ Christian H. Weiß weissc@hsu-hh.de

Tobias A. Möller moellert@hsu-hh.de

Maria Eduarda Silva mesilva@fep.up.pt

Manuel G. Scotto manuel.scotto@tecnico.ulisboa.pt

Isabel Pereira isabel.pereira@ua.pt

1 Department of Mathematics and Statistics, Helmut Schmidt University, Hamburg, Germany

2 Center for Research and Development in Mathematics and Applications (CIDMA), Faculty of Economics, University of Porto, Porto, Portugal

3 CEMAT and Department of Mathematics, IST University of Lisbon, Lisbon, Portugal

4 Center for Research and Development in Mathematics and Applications (CIDMA), Department of Mathematics, University of Aveiro, Aveiro, Portugal
} 


\section{Introduction}

Continuous-valued threshold autoregressive models have been extensively investigated in the literature, see the survey by Tong (2011). Some basic results on the probabilistic structure of this class of models can be found, e.g., in Chan et al. (1985), Chan and Tong (1985), Cline and Pu (1999, 2004), Lanne and Saikkonen (2005), Liebscher (2005), and in the books by Tong (1990), Turkman et al. (2014). Threshold models as proposed by Tong and Lim (1980), Tong (1983) have had an enormous influence in various fields of research in the past years caused by their excellent abilities to handle nonlinearity. They find usage in, e.g., actuarial science (Chan et al. 2004), biological sciences (Stenseth et al. 2006) as well as economics and finance (Chen et al. 2011; Hansen 2011) just to mention a few.

In the field of integer-valued time series modeling (with either bounded or unbounded range of counts), limited research has been carried out so far to develop models to cope with time series of counts exhibiting piecewise-type patterns. One such approach is hidden Markov models (HMM) for counts (Zucchini and MacDonald 2009), where a state dependence of the observed counts is introduced through an underlying (invisible) finite Markov chain (also see Sect. 5 below). While the HMMs are some kind of parameter-driven regime switching models, the threshold models being considered here are observation-driven regime switching models. Besides the threshold regression model by Samia et al. (2007), a few models being motivated by the autoregressive moving average (ARMA) approach have been proposed, see the survey by Möller and Weiß (2015). In particular, Monteiro et al. (2012) introduced the class of self-exciting threshold integer-valued autoregressive (SETINAR) models of order one and with two regimes, defined by the recursive equation

$$
X_{t}= \begin{cases}\alpha_{1} \circ X_{t-1}+Z_{t} & \text { if } X_{t-1} \leq R \\ \alpha_{2} \circ X_{t-1}+Z_{t} & \text { if } X_{t-1}>R\end{cases}
$$

Here, $\left(Z_{t}\right)$ constitutes a sequence of integer-valued random variables and $R$ represents the fixed threshold level separating the regimes. The " $\alpha \circ$ " is the binomial thinning operator of Steutel and Harn (1979). It is defined as $\alpha \circ X:=\sum_{i=1}^{X} Y_{i}$, for $X$ with range $\mathbb{N}_{0}=\{0,1, \ldots\}$, where the $Y_{i}$ 's are independent and identically distributed (i.i.d.) Bernoulli variables with probability $\alpha \in(0 ; 1)$. A similar SET approach related to the INAR(1) model was proposed by Thyregod et al. (1999). It is important to stress here that the models by Monteiro et al. (2012), Thyregod et al. (1999) as well as the other recently proposed ARMA-like models by Wang et al. (2014), Yu et al. (2014), Zou and $\mathrm{Yu}$ (2014) are useful for fitting integer-valued time series exhibiting the piecewise phenomena defined over an infinite range of counts.

However, these SETINAR models are of little use for modeling time series taking values over a finite range of counts. As an illustrative example of a time series of counts exhibiting two different regimes over a bounded interval, Fig. 1 shows a time series plot of the counts of districts in Germany in which at least one new case of measles was observed (weekly counts, 2004-2005); the data were downloaded from 


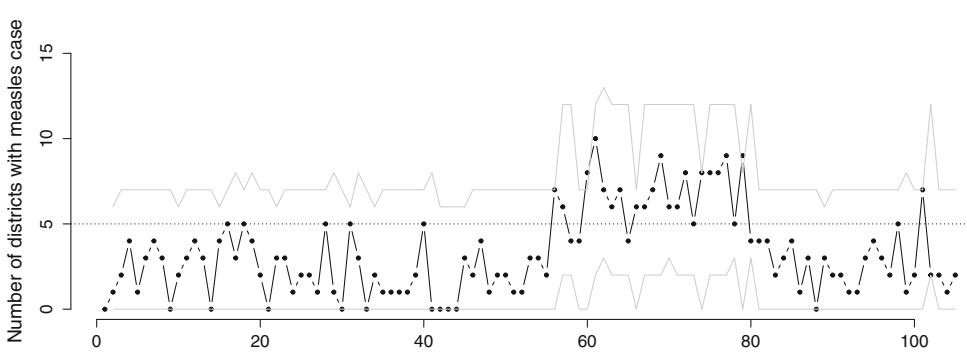

Fig. 1 Weekly number of districts in Germany with at least one new case of measles (2004-2005). Dotted line estimated threshold dividing the range into two regimes. Gray lines lower and upper limit of $95 \%$ forecast intervals for fitted LSET-BAR(1) model, see Sect. 5

SurvStat (Robert-Koch-Institut 2014). The time series consists of $T=105$ data points (53 weeks in 2004 and 52 weeks in 2005), taking values within the set $\{0, \ldots, N\}$ with $N=38$, where the fixed upper bound is determined through the given number of districts in Germany. A visual inspection of the time series reveals a level shift in the graphic corresponding to the first half of 2005, so it seems appropriate to mix integer-valued and threshold models for describing this data set.

Motivated by the aforementioned example, we shall propose a simple class of threshold autoregressive models for finite counts data based on McKenzie's binomial $\mathrm{AR}(1)[\mathrm{BAR}(1)]$ model. For the predetermined upper limit $N$ of the range, the latter model is defined by the recursion

$$
X_{t}=\alpha \circ X_{t-1}+\beta \circ\left(N-X_{t-1}\right),
$$

for $\pi \in(0 ; 1), r \in\left(\max \left\{-\frac{\pi}{1-\pi},-\frac{1-\pi}{\pi}\right\} ; 1\right)$ and $\beta:=\pi(1-r), \alpha:=\beta+r$. Here, all thinnings are performed independently of each other, and the thinnings at time $t$ are independent of $\left(X_{S}\right)_{s<t}$. Note that the representation for $X_{t}$ in (1) guarantees that the range of $X_{t}$ is given by the set $\{0,1, \ldots, N\}$. Furthermore, the condition on $r$ guarantees that the thinning parameters $\alpha, \beta \in(0 ; 1)$. The parameter $\alpha$ can be interpreted as a survival rate, and $\beta$ as a recolonization rate. The process in (1) is a stationary Markov chain with $N+1$ states and binomial marginal distribution $B(N, \pi)$. The BAR(1) process shares important properties with the conventional AR(1) model, e.g., that the autocorrelation function (ACF) $\rho(k)=r^{k}$ decays to 0 at an exponential rate.

The rest of the paper is organized as follows: In Sect. 2, diverse self-exciting threshold versions of the BAR(1) model (1) are introduced and investigated in detail. Parameter estimation and model specification are addressed in Sect. 3, while Sect. 4 deals with approaches for forecasting. In Sect. 5, we consider again the measles data shown in Fig. 1 and compare our models to competing models. Section 6 presents possible extensions of our basic self-exciting threshold models, e.g., with higher delays, or for the case of bivariate counts. The article closes with some concluding remarks in Sect. 7. 


\section{A basic self-exciting threshold binomial AR(1) model}

Based on the BAR(1) model (1), we build our extension by introducing a self-exciting threshold mechanism. For the moment, we restrict to a basic model, where the finite range is separated into two regimes, and where the state of the process is selected according to the previous observation (delay 1); later in Sect. 6, a number of possible extensions of our basic model are presented. The two regimes are determined by a specified threshold value $0 \leq R<N$ : The lower regime consists of the states $\{0,1,2, \ldots, R\}$, and the upper regime consists of $\{R+1, R+2, \ldots, N\}$. In each regime, the model takes individual values for the survival rate $\alpha_{i}$ and for the recolonization rate $\beta_{i}$.

\subsection{The SET binomial AR(1) model}

We start with the most general definition of our basic self-exciting threshold binomial AR(1) model (SET-BAR), i.e., a univariate model having two regimes and delay parameter 1. Later in Sect. 6, we discuss possible extensions to higher-order autoregressions, to delays $d>1$, to more than two regimes, and to the bivariate case.

Definition 2.1 Let $N \in \mathbb{N}$ be the predetermined upper limit of the range, and let $0 \leq$ $R<N$ be the threshold value. Define $\pi_{i} \in(0 ; 1), r_{i} \in\left(\max \left\{-\frac{\pi_{i}}{1-\pi_{i}},-\frac{1-\pi_{i}}{\pi_{i}}\right\} ; 1\right)$, as well as $\beta_{i}:=\pi_{i} \cdot\left(1-r_{i}\right) \in(0 ; 1)$ and $\alpha_{i}:=\beta_{i}+r_{i} \in(0 ; 1)$ for $i \in\{1,2\}$. A process $\left(X_{t}\right)$ is called a SET-BAR(1) process if $X_{t}$ follows the recursion

$$
X_{t}=\phi_{t} \circ X_{t-1}+\eta_{t} \circ\left(N-X_{t-1}\right) \text { for } t \in \mathbb{Z} \text {, }
$$

where $\phi_{t}:=\alpha_{1} I_{t-1}+\alpha_{2}\left(1-I_{t-1}\right)$ and $\eta_{t}:=\beta_{1} I_{t-1}+\beta_{2}\left(1-I_{t-1}\right)$ with $I_{t-1}:=$ $\mathbb{1}_{\left\{X_{t-1} \leq R\right\}}$ as the indicator variable.

Note that, in the case $R=0$, the parameter $\alpha_{1}$ has no influence on the model and hence can be chosen arbitrarily, which, in turn, makes $\alpha_{1}$ unidentifiable during the parameter estimation process. The same issue occurs for $\beta_{2}$ in the case $R=N-1$. To circumvent these problems, we set $r_{1}=r_{2}$ for the threshold values $R=0, N-1$, i.e., we use the LSET model as introduced in Sect. 2.2 below. In all remaining cases, the parameters are identifiable as long as there is a sufficient number of different observations in each regime.

Since the SET-BAR(1) model falls within the class of density-dependent binomial AR(1) [DD-BAR(1)] models as introduced by Weiß and Pollett (2014), ${ }^{1}$ it follows by expression (1) in Weiß and Pollett (2014) that the transition probabilities $p_{k \mid l}:=$ $P\left(X_{t}=k \mid X_{t-1}=l\right)$ of the SET-BAR(1) process take the form

$$
p_{k \mid l}=\sum_{m=\max \{0, k+l-N\}}^{\min \{k, l\}}\left(\begin{array}{l}
l \\
m
\end{array}\right)\left(\begin{array}{l}
N-l \\
k-m
\end{array}\right) \phi_{t}^{m}\left(1-\phi_{t}\right)^{l-m} \eta_{t}^{k-m}\left(1-\eta_{t}\right)^{N-l+m-k}>0 .
$$

\footnotetext{
1 The density-dependent models by Weiß and Pollett (2014) might also be understood as special SET models with $N+1$ regimes.
} 
Note that the $(N+1) \times(N+1)$-dimensional transition matrix $\mathbf{P}:=\left(p_{k \mid l}\right)_{k, l=0, \ldots, N}$ is primitive so that the process is ergodic with uniquely determined stationary marginal distribution $\boldsymbol{p}$. Since it is hardly possible to obtain a closed-form expression for the stationary marginal distribution $\boldsymbol{p}$, we determine it numerically by solving the eigenvalue problem $\mathbf{P} \boldsymbol{p}=\boldsymbol{p}$.

Next, we derive marginal conditional moments. From expression (2) in Weiß and Pollett (2014), we obtain

$$
\begin{aligned}
E\left[X_{t} \mid X_{t-1}\right]= & I_{t-1}\left(r_{1} X_{t-1}+\left(1-r_{1}\right) \pi_{1} N\right)+\left(1-I_{t-1}\right)\left(r_{2} X_{t-1}+\left(1-r_{2}\right) \pi_{2} N\right), \\
V\left[X_{t} \mid X_{t-1}\right]= & I_{t-1}\left(r_{1}\left(1-r_{1}\right)\left(1-2 \pi_{1}\right) X_{t-1}+N\left(1-r_{1}\right) \pi_{1}\left(1-\left(1-r_{1}\right) \pi_{1}\right)\right) \\
& +\left(1-I_{t-1}\right)\left(r_{2}\left(1-r_{2}\right)\left(1-2 \pi_{2}\right) X_{t-1}\right. \\
& \left.+N\left(1-r_{2}\right) \pi_{2}\left(1-\left(1-r_{2}\right) \pi_{2}\right)\right) .
\end{aligned}
$$

Now we are prepared to obtain the unconditional mean and the variance of the stationary process. For simplicity in notation, we define $p:=P\left(X_{t} \leq R\right)=E\left[I_{t-1}\right]$, $\mu_{X}:=E\left[X_{t}\right], \sigma_{X}^{2}:=V\left[X_{t}\right]$, and the partial moments $\mu_{I X}:=E\left[I_{t-1} X_{t-1}\right]$, $\mu_{I X, 2}:=E\left[I_{t-1} X_{t-1}^{2}\right]$. Then, unconditional mean and variance are given by

$$
\begin{aligned}
\mu_{X}= & \frac{r_{1}-r_{2}}{1-r_{2}} \mu_{I X}+N\left(p \pi_{1} \frac{1-r_{1}}{1-r_{2}}+(1-p) \pi_{2}\right) \\
\left(1-r_{2}^{2}\right) \sigma_{X}^{2}= & r_{2}\left(1-r_{2}\right)\left(1-2 \pi_{2}\right) \mu_{X}-2 N p r_{2}\left(\left(1-r_{1}\right) \pi_{1}-\left(1-r_{2}\right) \pi_{2}\right) \mu_{X} \\
& -2 r_{2}\left(r_{1}-r_{2}\right) \mu_{X} \mu_{I X}+\left(r_{1}^{2}-r_{2}^{2}\right) \mu_{I X, 2}-\left(r_{1}-r_{2}\right)^{2} \mu_{I X}^{2} \\
& +2 N\left(r_{1}-p\left(r_{1}-r_{2}\right)\right)\left(\left(1-r_{1}\right) \pi_{1}-\left(1-r_{2}\right) \pi_{2}\right) \mu_{I X} \\
& +\left(r_{1}\left(1-r_{1}\right)\left(1-2 \pi_{1}\right)-r_{2}\left(1-r_{2}\right)\left(1-2 \pi_{2}\right)\right) \mu_{I X} \\
& +N p\left(1-r_{1}\right) \pi_{1}\left(1-\left(1-r_{1}\right) \pi_{1}\right) \\
& +N(1-p)\left(1-r_{2}\right) \pi_{2}\left(1-\left(1-r_{2}\right) \pi_{2}\right) \\
& +N^{2} p(1-p)\left(\left(1-r_{1}\right) \pi_{1}-\left(1-r_{2}\right) \pi_{2}\right)^{2} .
\end{aligned}
$$

The proof of (6) and (7) can be found in "Unconditional mean and variance" section of Appendix 1. Keep in mind that $p$ strongly depends on $\pi_{1}$ and $\pi_{2}$.

\subsection{The LSET binomial AR(1) model}

Looking at Fig. 1, it becomes clear that the level of the measles time series is shifted in the first half of 2005, while there is no obvious change in the serial dependence structure. This motivates to consider the model in Definition 2.1 but with the additional restriction $r_{1}=r_{2}=: r$ with $r \in\left(\max \left\{-\frac{\pi_{1}}{1-\pi_{1}},-\frac{\pi_{2}}{1-\pi_{2}},-\frac{1-\pi_{1}}{\pi_{1}},-\frac{1-\pi_{2}}{\pi_{2}}\right\} ; 1\right)$. Notice that we will not have to consider the complicated restriction on the left-hand side of the interval for $r$ if we only use positive values for the dependence parameter $r$.

The restriction $r_{1}=r_{2}$ is attractive to keep the number of model parameters low. It implies that $\alpha_{1}-\beta_{1}=\alpha_{2}-\beta_{2}$ and that $\beta_{2}-\beta_{1}=\left(\pi_{2}-\pi_{1}\right)(1-r)$. Since only 
the level of the process is shifted, we will refer to this model as the level SET-BAR(1) model, abbreviated as LSET-BAR(1) model.

Definition 2.2 A SET-BAR(1) process for which $r_{1}=r_{2}=: r \neq 0$ holds is called an LSET-BAR(1) process.

Although in this case, the transition probabilities in (3) do not change much, we get more simple expressions for the conditional moments (4) and (5):

$$
\begin{aligned}
E\left[X_{t} \mid X_{t-1}\right]= & r X_{t-1}+N(1-r)\left(I_{t-1} \pi_{1}+\left(1-I_{t-1}\right) \pi_{2}\right), \\
V\left[X_{t} \mid X_{t-1}\right]= & I_{t-1}\left(r(1-r)\left(1-2 \pi_{1}\right) X_{t-1}+N(1-r) \pi_{1}\left(1-(1-r) \pi_{1}\right)\right) \\
& +\left(1-I_{t-1}\right)\left(r(1-r)\left(1-2 \pi_{2}\right) X_{t-1}\right. \\
& \left.+N(1-r) \pi_{2}\left(1-(1-r) \pi_{2}\right)\right) .
\end{aligned}
$$

In particular, unconditional mean (6) and variance (7) can be simplified a lot for a stationary LSET-BAR(1) process $\left(X_{t}\right)$; see "Unconditional mean and variance" section of Appendix 1:

$$
\begin{aligned}
\mu_{X}= & N p \pi_{1}+N(1-p) \pi_{2}, \\
\sigma_{X}^{2}= & N p \pi_{1}\left(1-\pi_{1}\right)+N(1-p) \pi_{2}\left(1-\pi_{2}\right)+N^{2} p(1-p)\left(\pi_{2}-\pi_{1}\right)^{2} \\
& +\frac{2 r}{1+r}(N-1)\left(\pi_{2}-\pi_{1}\right)\left(N p \pi_{1}-\mu_{I X}\right) .
\end{aligned}
$$

In view of the practical relevance of the parsimonious LSET model, additional stochastic properties are derived in Sect. 2.4 below.

\subsection{The $\operatorname{LSET}^{0}$ binomial AR(1) model}

Relations (8) and (9) highlight that the case $r=0$ has to be treated separately. In contrast to the usual BAR(1) model, where $r=0$ corresponds to serial independence, an LSET-BAR(1) model with $r=0$ still exhibits dependence on $X_{t-1}$, but only through the indicator function $I_{t-1}$, whereas the concrete value of $X_{t-1}$ is without influence.

Definition 2.3 A SET-BAR(1) process with $r_{1}=r_{2}=0$ is said to be an $\mathrm{LSET}^{0}$ BAR(1) process.

Notice that this model has only two parameters, namely $\pi_{1}=\alpha_{1}=\beta_{1}$ and $\pi_{2}=$ $\alpha_{2}=\beta_{2}$. So depending on whether $X_{t-1} \leq R$ or $X_{t-1}>R$, the next count $X_{t}$ is generated from either $B\left(N, \pi_{1}\right)$ or $B\left(N, \pi_{2}\right)$, respectively. If, for instance, $R=0$, the $\mathrm{LSET}^{0}$ model allows for a simple way of causing zero inflation or zero deflation.

Conditional mean and variance follow from (8) and (9) as

$$
\begin{aligned}
E\left[X_{t} \mid X_{t-1}\right] & =N\left(I_{t-1} \pi_{1}+\left(1-I_{t-1}\right) \pi_{2}\right), \\
V\left[X_{t} \mid X_{t-1}\right] & =I_{t-1}\left(N \pi_{1}\left(1-\pi_{1}\right)\right)+\left(1-I_{t-1}\right)\left(N \pi_{2}\left(1-\pi_{2}\right)\right) .
\end{aligned}
$$


The unconditional mean (10) remains as before, but the unconditional variance (11) simplifies to

$$
\sigma_{X}^{2}=N p \pi_{1}\left(1-\pi_{1}\right)+N(1-p) \pi_{2}\left(1-\pi_{2}\right)+N^{2} p(1-p)\left(\pi_{2}-\pi_{1}\right)^{2} .
$$

We conclude our discussion by pointing out the analogy of the $\mathrm{LSET}^{0}$ model to the "piecewise constant AR model" in Example 4.3 in Tong (2011) as well as to the "martingale difference model" (Tong 2011, Example 4.4) [also see the more general threshold model for conditional heteroscedasticity ("T-CHARM") in Chan et al. 2014]. But while the latter models only change either the conditional mean or the conditional variance, the $\mathrm{LSET}^{0}$ model changes conditional mean and conditional variance simultaneously due to the conditional binomial distribution.

\subsection{Further properties of the LSET-BAR(1) model}

Let us look back to the LSET-BAR(1) model according to Definition 2.2. The binomial index of dispersion, BID, is a useful metric when quantifying the dispersion behavior of count data random variables with a finite range $\{0, \ldots, N\}$. It is defined as

$$
\mathrm{BID} \equiv \operatorname{BID}\left(N, \mu, \sigma^{2}\right)=\frac{N \sigma^{2}}{\mu(N-\mu)}=\frac{\sigma^{2}}{\mu\left(1-\frac{\mu}{N}\right)} \quad>0 .
$$

For the binomial distribution, it holds that $\mathrm{BID}=1$. A distribution with finite range is said to have overdispersion if BID $>1$ (also extra-binomial variation), it is equidispersed if $\mathrm{BID}=1$, and it is underdispersed if $\mathrm{BID}<1$, each with respect to the binomial distribution.

For the LSET-BAR(1) model, the BID follows from (10) and (11) as

$$
\mathrm{BID}=1+\frac{N(N-1) p(1-p)\left(\pi_{2}-\pi_{1}\right)^{2}+\frac{2 r}{1+r}(N-1)\left(\pi_{2}-\pi_{1}\right)\left(N p \pi_{1}-\mu_{I X}\right)}{N p \pi_{1}\left(1-\pi_{1}\right)+N(1-p) \pi_{2}\left(1-\pi_{2}\right)+N p(1-p)\left(\pi_{2}-\pi_{1}\right)^{2}},
$$

see "Binomial index of dispersion" section of Appendix 1. Note that for $r \in$ $(0 ; 1)$, underdispersion is only possible for $\pi_{2}<\pi_{1}$. In contrast, for $r \in$ $\left(\max \left\{-\frac{\pi_{1}}{1-\pi_{1}},-\frac{\pi_{2}}{1-\pi_{2}},-\frac{1-\pi_{1}}{\pi_{1}},-\frac{1-\pi_{2}}{\pi_{2}}\right\} ; 0\right)$, underdispersion is only possible for $\pi_{2}>\pi_{1}$. For $r=0$ (LSET ${ }^{0}$ model, see Definition 2.3), the model always shows overdispersion provided that $\pi_{1} \neq \pi_{2}$.

Solving now the equation BID $=1$ in order to $x:=\pi_{2}-\pi_{1}$, it follows that

$$
\begin{aligned}
0 & =N(N-1) p(1-p) \cdot x^{2}+\frac{2 r}{1+r}(N-1)\left(N p \pi_{1}-\mu_{I X}\right) \cdot x \\
\Leftrightarrow x & =0 \quad\left(\Leftrightarrow \pi_{1}=\pi_{2}\right) \quad \text { or } \quad x=-\frac{\frac{2 r}{1+r}\left(N p \pi_{1}-\mu_{I X}\right)}{N p(1-p)} .
\end{aligned}
$$




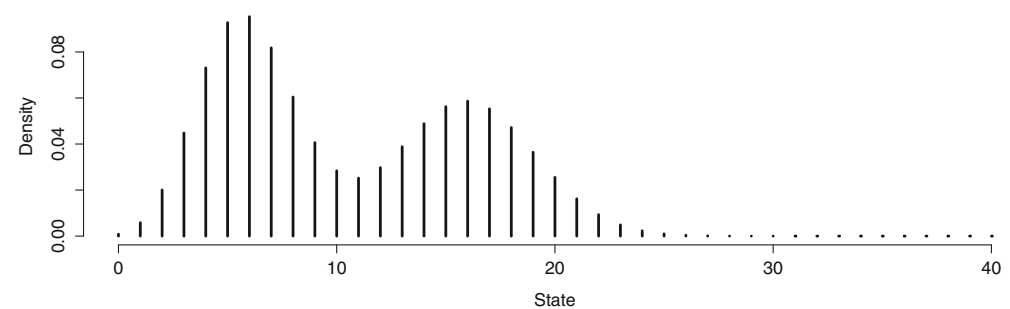

Fig. 2 PMF of LSET-BAR(1) model with $N=40, r=0.3, \pi_{1}=0.15, \pi_{2}=0.4$, and with threshold $R=10$. For this model, we have $p \approx 0.54, \mu_{I X} \approx 3.21, \mu_{X} \approx 10.56$ and BID $\approx 4.14$

This result implies that for parameter values lying between these two roots, the process is underdispersed. In a nutshell, the LSET model is able to show over- and underdispersion for appropriate parameter settings.

Like for the continuous threshold models, we observed that the probability mass function (PMF) of the LSET-BAR(1) process may have multiple modes (see Fig. 2 as an example). In analogy to Tong and Lim (1980), we define the skeleton of the LSET-BAR(1) model as

$$
x_{t}=r x_{t-1}+\left\{\begin{array}{ll}
(1-r) \pi_{1} N & \text { if } x_{t-1} \leq R \\
(1-r) \pi_{2} N & \text { if } x_{t-1}>R
\end{array} .\right.
$$

We studied the limit cycles of the skeleton Tong and Lim (1980) aiming to find relations between the location of the modes and the elements in the limit cycle. However, it was not possible to establish a unique relation between the modes and limit cycles.

Finally, we investigate the ACF $\rho(k)$ for the LSET-BAR(1) model. In "Autocovariance function" section of Appendix 1, it is proved that

$$
\rho(k)=r^{k}+\frac{N(1-r)\left(\pi_{1}-\pi_{2}\right)}{\sigma_{X}^{2}} \cdot \sum_{s=1}^{k} r^{s-1} \operatorname{Cov}\left[I_{t-s}, X_{t-k}\right]
$$

where $\sigma_{X}^{2}=V\left[X_{t}\right]$ and $I_{t-s}=\mathbb{1}_{\left\{X_{t-s} \leq R\right\}}$. The ACF in (18) reduces to the well-known $\mathrm{AR}(1)$-like ACF of the BAR(1) model for $\pi_{1}=\pi_{2}$. Otherwise, the ACF differs from the function $f(k):=(\rho(1))^{k}$ as it would be expected from an $\mathrm{AR}(1)$-like model. The model in Fig. 3, for instance, has longer memory than a corresponding AR(1)-like model.

For the $\mathrm{LSET}^{0}$-BAR(1) model, the ACF takes the form

$$
\left.\rho(k)\right|_{r=0}=\frac{N\left(\pi_{1}-\pi_{2}\right)}{\sigma_{X}^{2}} \operatorname{Cov}\left[I_{t-1}, X_{t-k}\right] .
$$




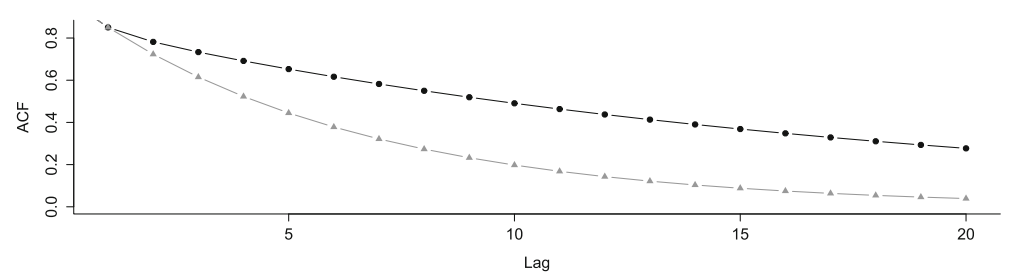

Fig. 3 ACF of LSET-BAR(1) model from Fig. 2, i.e., with $N=40, r=0.3, \pi_{1}=0.15, \pi_{2}=0.4$ and $R=10$ (black dots). Gray triangles show $f(k):=(\rho(1))^{k}$

\section{Parameter estimation and model specification for SET-BAR(1) models}

In this section, we consider first parameter estimation in the SET-BAR(1) model using conditional least squares (CLS) and conditional maximum likelihood (CML) methods. Later, we will take a look at a likelihood ratio test in view of uncovering nonlinearities.

\subsection{Conditional least squares and maximum likelihood estimation}

Let $X_{0}, X_{1}, \ldots, X_{T}$ be the available segment from the SET-BAR(1) process with vector of unknown parameters $\boldsymbol{\theta}:=\left(r_{1}, r_{2}, \pi_{1}, \pi_{2}\right)$ taking values in

$$
\Theta:=\left(\max \left\{-\frac{\pi_{1}}{1-\pi_{1}},-\frac{1-\pi_{1}}{\pi_{1}}\right\} ; 1\right) \times\left(\max \left\{-\frac{\pi_{2}}{1-\pi_{2}},-\frac{1-\pi_{2}}{\pi_{2}}\right\} ; 1\right) \times(0 ; 1)^{2} .
$$

For now, we assume a fixed threshold $R$ (later we drop this assumption). Note that the alternative parameterization of the full SET model, with parameter vector $\boldsymbol{\theta}:=$ $\left(\alpha_{1}, \alpha_{2}, \beta_{1}, \beta_{2}\right)$, would have the practical advantage that $\left(\alpha_{1}, \alpha_{2}, \beta_{1}, \beta_{2}\right)$ has to satisfy the box constraint $(0 ; 1)^{4}$.

The CLS estimators $\hat{\boldsymbol{\theta}}_{\mathrm{CLS}}$ are obtained by numerically minimizing the sum of the squared deviations

$$
Q(\boldsymbol{\theta}):=\sum_{t=1}^{T}\left(X_{t}-g\left(\boldsymbol{\theta}, X_{t-1}\right)\right)^{2} \equiv \sum_{t=1}^{T} U_{t}^{2}
$$

with respect to $\boldsymbol{\theta}$, where $g\left(\boldsymbol{\theta}, X_{t-1}\right):=E\left[X_{t} \mid X_{t-1}\right]$ is given by (4). Since the SETBAR(1) process is stationary and ergodic, it follows from Theorems 3.1 and 3.2 in Klimko and Nelson (1978) that $\hat{\boldsymbol{\theta}}_{\mathrm{CLS}}$ is a consistent and asymptotically normal estimator of $\boldsymbol{\theta}$, i.e.,

$$
\sqrt{T}\left(\hat{\boldsymbol{\theta}}_{\mathrm{CLS}}-\boldsymbol{\theta}\right) \stackrel{d}{\rightarrow} N\left(\mathbf{0}, \mathbf{V}^{-1} \mathbf{W} \mathbf{V}^{-1}\right),
$$

where $\mathbf{V}$ and $\mathbf{W}$ are $4 \times 4$ squared matrices with the $i j$ th element given by

$$
\begin{aligned}
V_{i j} & =E\left[\frac{\partial}{\partial \theta_{i}} g\left(\boldsymbol{\theta}, X_{t-1}\right) \frac{\partial}{\partial \theta_{j}} g\left(\boldsymbol{\theta}, X_{t-1}\right)\right], \\
W_{i j} & =E\left[U_{t}^{2} \frac{\partial}{\partial \theta_{i}} g\left(\boldsymbol{\theta}, X_{t-1}\right) \frac{\partial}{\partial \theta_{j}} g\left(\boldsymbol{\theta}, X_{t-1}\right)\right] .
\end{aligned}
$$


Similar arguments apply to the LSET models with their reduced number of parameters.

Consider now the conditional maximum likelihood (CML) method to estimate the unknown model parameters $\boldsymbol{\theta}$. The CML estimators are obtained maximizing the conditional log-likelihood function

$$
\ell(\boldsymbol{\theta}):=\log L\left(\boldsymbol{\theta} ; x_{0}\right) \equiv \sum_{t=1}^{T} \ln P_{\boldsymbol{\theta}}\left(X_{t}=x_{t} \mid X_{t-1}=x_{t-1}\right)
$$

with the transition probabilities defined in (3), i.e., they solve the following maximization problem:

$$
\hat{\boldsymbol{\theta}}=\arg \max _{\boldsymbol{\theta} \in \Theta} \ell(\boldsymbol{\theta}) .
$$

Note that no closed-form expressions for the estimates can be found, so numerical procedures have to be employed. In order to prove the existence and consistency of the CML estimators, it is sufficient to show that Condition 5.1 of Billingsley (1961) holds. If Condition 5.1 holds, then Theorems 2.1 and 2.2 of Billingsley (1961) guarantee that there exists a consistent CML estimator being asymptotically normally distributed,

$$
\sqrt{T}\left(\hat{\boldsymbol{\theta}}_{\mathrm{ML}}-\boldsymbol{\theta}\right) \stackrel{d}{\rightarrow} N\left(\mathbf{0}, \mathbf{I}_{1}^{-1}(\boldsymbol{\theta})\right),
$$

where $\mathbf{I}_{1}(\boldsymbol{\theta})$ denotes the expected Fisher information. Condition 5.1 of Billingsley (1961) is fulfilled provided that

1. the set $D$ of $(k, l)$ such that $p_{k \mid l}(\boldsymbol{\theta})>0$ is independent of $\boldsymbol{\theta}$;

2. each $p_{k \mid l}(\boldsymbol{\theta})$ has continuous partial derivatives of third-order throughout $\Theta$;

3. the $d \times w$ matrix

$$
\left(\frac{\partial p_{k \mid l}(\boldsymbol{\theta})}{\partial \theta_{u}}\right)_{(k, l) \in D, u=1, \ldots, w}
$$

has rank $w$ throughout $\Theta$, where $d:=|D|$ and $w:=\operatorname{dim}(\Theta)$;

4. for each $\boldsymbol{\theta} \in \Theta$, there is only one ergodic set and there are no transient states.

Conditions 1 and 4 are fulfilled since all $p_{k \mid l}>0$ as stated earlier, while Condition 2 holds due to the polynomial structure of the $p_{k \mid l}$. The third condition is also fulfilled if we exclude trivial cases such as $\pi_{1}=\pi_{2}$ [BAR(1) model] or $r=0$ (LSET ${ }^{0}$ BAR(1) model). Note that CML estimation for the usual BAR(1) model was already investigated by Weiß and Kim (2013). For the $\mathrm{LSET}^{0}$ model, the parameter vector reduces to $\boldsymbol{\theta}=\left(\pi_{1}, \pi_{2}\right) \in(0 ; 1)^{2}$, and we have $w=2$ in this case.

For the numerical maximization of the log-likelihood (23), we use the R function optim with the expected Fisher information I in (25) being approximated by the negative Hessian of the log-likelihood at the maximum (observed Fisher information). The initial estimates required by such numerical procedures are obtained by the CLS approach.

Next, we turn to the estimation of the threshold parameter. Note that $R$ is a discretevalued parameter in our case. Hence, it cannot be directly included in the parameter set 
(a)

\begin{tabular}{cccccc}
\hline Model & $N$ & $r$ & $\pi_{1}$ & $\pi_{2}$ & $R$ \\
\hline M1 & 40 & 0.3 & 0.15 & 0.4 & 10 \\
M2 & 20 & 0.3 & 0.15 & 0.4 & 4 \\
M3 & 40 & 0.7 & 0.15 & 0.4 & 10 \\
M4 & 20 & 0.7 & 0.15 & 0.4 & 5 \\
\hline
\end{tabular}

(c)

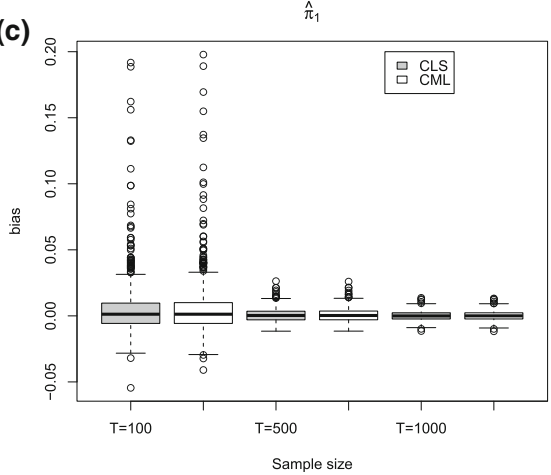

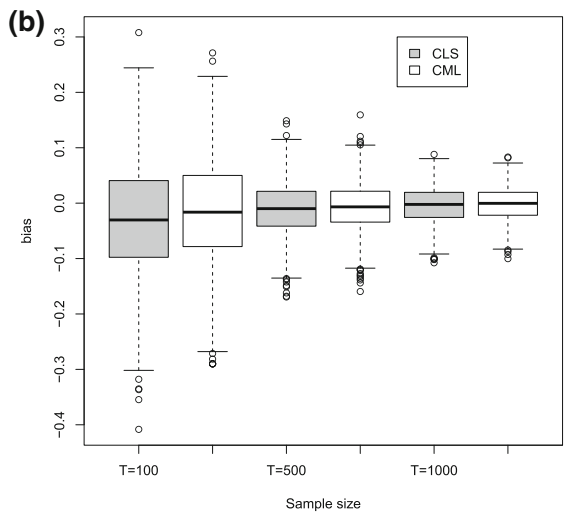

(d)

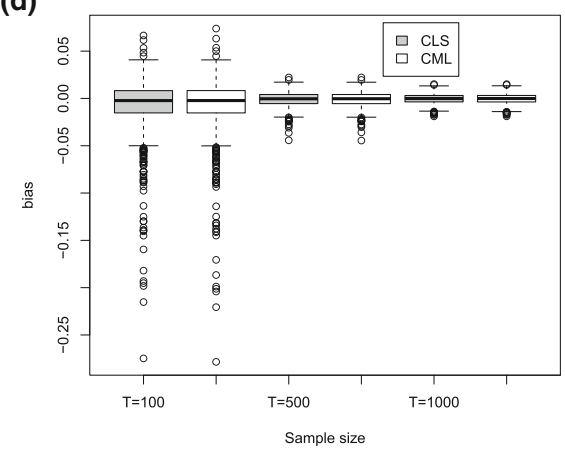

Fig. 4 a Set of parameters for LSET-BAR(1) model. b-d Boxplots of estimates for $r, \pi_{1}$ and $\pi_{2}$ for model M1, with threshold set to its true value, $R=10$

$\Theta$ of the above CLS or CML approaches; this is in contrast to the case of continuousvalued SET models, see, e.g., Chan et al. (2014). So in order to estimate $R$, we considered the same approach as Wang et al. (2014). Both CLS and CML estimations are performed for different values of $R$ in a reasonable set which depends on the application. Finally, we choose the threshold value $R$ as the value that delivers the lowest $Q(\hat{\boldsymbol{\theta}})$ or the lowest $-\ell_{\max }$, respectively.

To illustrate the estimation procedures and small sample properties of the estimators, we focus on the LSET-BAR(1) models with parameters

$$
\boldsymbol{\theta}=\left(r, \pi_{1}, \pi_{2}\right) \in \Theta:=\left(\max \left\{-\frac{\pi_{1}}{1-\pi_{1}},-\frac{\pi_{2}}{1-\pi_{2}},-\frac{1-\pi_{1}}{\pi_{1}},-\frac{1-\pi_{2}}{\pi_{2}}\right\} ; 1\right) \times(0 ; 1)^{2}
$$

and $R$ as given in Fig. 4a (note that model M1 is the one from Fig. 2). In total, 1000 independent replicates of time series of length 100, 500 and 1000 are generated from each model, and the parameters are estimated by CLS and CML. Regarding the set of values for the threshold parameter $R$, we consider 5 values centered in the true value of $R$. 
The results are summarized in Tables 5, 6, 7 and 8 in Appendix 2, while Fig. 4b-d displays boxplots of the biases for $\hat{\boldsymbol{\theta}}$. The tables report for each model the (mean) estimates and corresponding standard errors and, for each value of $R$, the percentage of series for which $R$ leads to the minimum $Q(\hat{\boldsymbol{\theta}})$ in the CLS or the lowest $-\ell_{\max }$ in the CML estimation. First, note that the strategy to estimate $R$ allows choosing the correct value most of the times already for small sample sizes, and this hit rate quickly approaches $100 \%$ for increasing $T$. This is similar to the case of the SETPAR models studied by Wang et al. (2014), where a formal proof of the consistency of the estimation approach for $R$ is given. Tables 5, 6, 7 and 8 also illustrate the unbiasedness and consistency of the estimators $\hat{\boldsymbol{\theta}}$, since the bias and standard errors decrease to zero as $T$ increases. Furthermore, Fig. 4 illustrates the small sample properties of the estimators: The componentwise estimates tend to be unbiased and consistent. The results furthermore indicate that the CLS estimates present larger biases than CML when obtained under an incorrect value of the threshold.

\subsection{Likelihood ratio test}

Let us now tackle the issue of testing for nonlinearity in the data. Petruccelli (1990) investigated the performance of different tests for SETAR-type nonlinearity and concluded that the likelihood ratio (LR) test was one of the best performers. Hence, we consider an LR test in the sequel, with the null hypothesis of a BAR(1) model. In order to prove the applicability of the test, we consider again the results in Billingsley (1961). Let $\Phi$ be the parameter set of the BAR(1) model and $\Theta$ be the one of the SET-BAR(1) model with specified threshold value $R$. We can define $h: \Phi \rightarrow \Theta$ as a mapping from $\Phi$ into $\Theta$ in such a way that $r_{1}=r_{2}=r$ and $\pi_{1}=\pi_{2}=\pi$. This mapping satisfies Condition 3.1 of Billingsley (1961). Together with Condition 5.1, which is fulfilled as already shown before, Theorem 5.2 of Billingsley (1961) is applicable: If $\boldsymbol{\theta}^{0}=h\left(\boldsymbol{\phi}^{0}\right)$ is the true parameter value, then

$$
2\left(\max _{\Theta} \ell-\max _{\Phi} \ell\right) \stackrel{d}{\rightarrow} \chi_{w-c}^{2}
$$

where $w:=\operatorname{dim}(\Theta)$ and $c:=\operatorname{dim}(\Phi)$. For the set model, $w=4$ and $c=2$, so the LR statistic converges to a $\chi_{2}^{2}$ distribution. If we choose the LSET model instead, we have a convergence to a $\chi_{1}^{2}$ distribution. The finite-sample performance of the LR test is briefly considered in Sect. 5 below.

\section{Forecasting for SET-BAR(1) models}

To forecast a SET-BAR(1) process, we use the forecasting distributions over all horizons $h \in \mathbb{N}$, i.e., the probabilistic distribution of $X_{T+h}$ based on the observed time series up to time $T$ ("more-than-one-step-ahead predictive distributions," see Tong 2011). This approach leads to forecasts being themselves counts and therefore being coherent with the sample space. It also allows the quantification of the uncertainty 

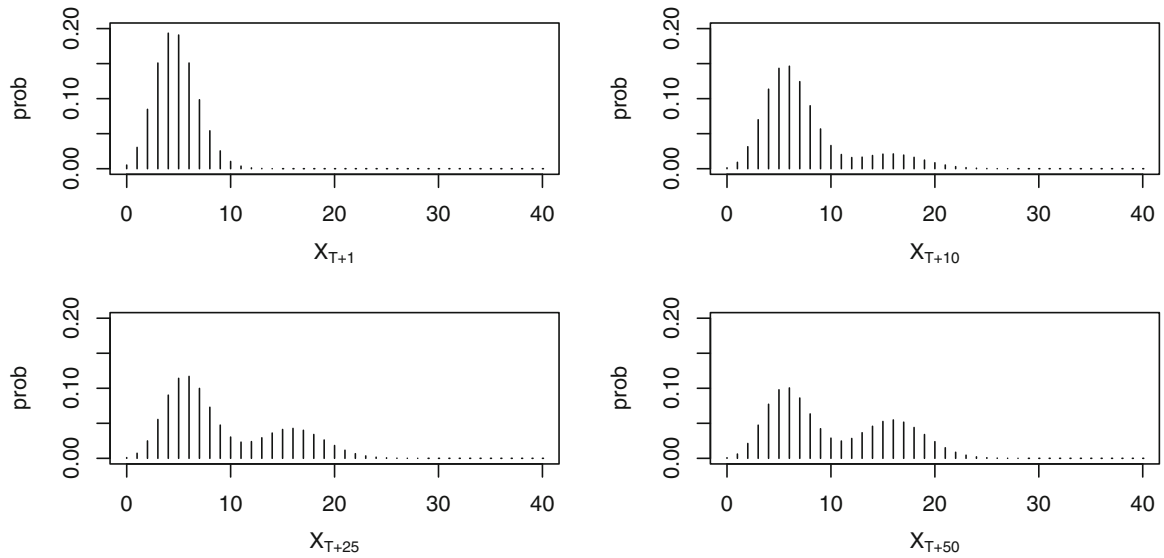

Fig. 5 Forecasting distributions for model M1 conditional on $X_{T}=2$
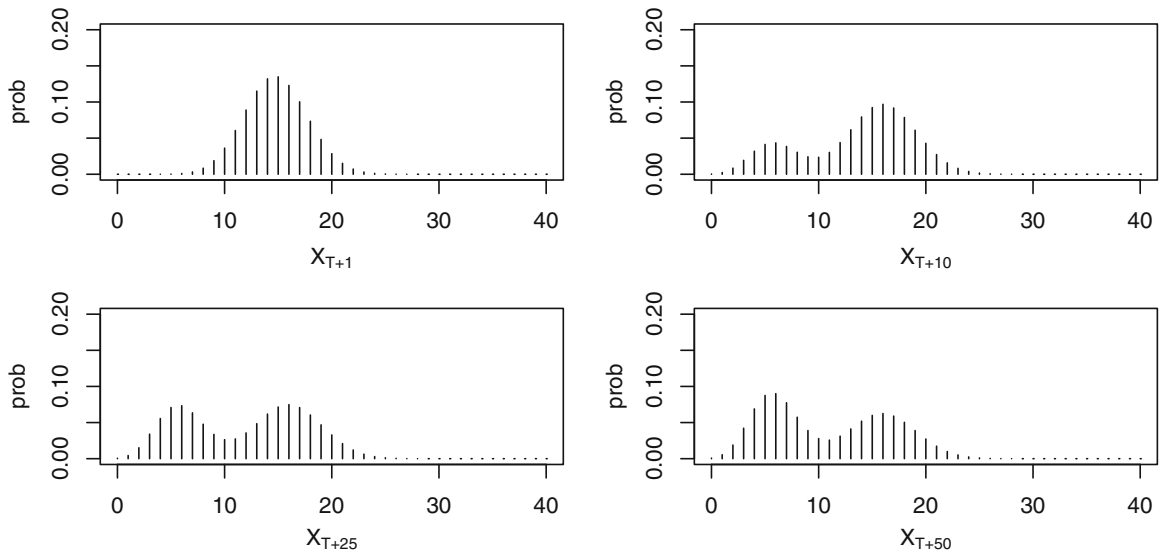

Fig. 6 Forecasting distributions for model M1 conditional on $X_{T}=12$

associated with the future counts, which is important in a context of risk analysis. Point forecasts, if needed, are easily obtained from the median or the mode of the forecasting distribution. For the SET-BAR(1) process, the $h$-step-ahead conditional distribution of $X_{T+h}$ given $X_{T}$ is given by

$$
P\left(X_{T+h}=x_{T+h} \mid X_{T}=x_{T}\right)=\left[\mathbf{P}^{h}\right]_{x_{T+h}, x_{T}},
$$

where $\mathbf{P}$ denotes the transition matrix defined via (3). To prove (27), note that the conditional distribution of $X_{T+h}$ given $X_{T}$ satisfies the Chapman-Kolmogorov equations, since we are concerned with a homogeneous Markov chain.

As an illustration, Figs. 5 and 6 represent the forecasting distributions for the horizons $h=1,10,25,50$ steps ahead for model M1, i.e., $\left(N, R ; r, \pi_{1}, \pi_{2}\right)=$ $(40,10 ; 0.3,0.15,0.4)$, conditioned on an observation in each of the two regimes, $X_{T}=2$ and $X_{T}=12$, respectively. The figures show how, for growing $h$, these 
Table 1 Estimated bias and MSEs for median forecasts in models M1-M4

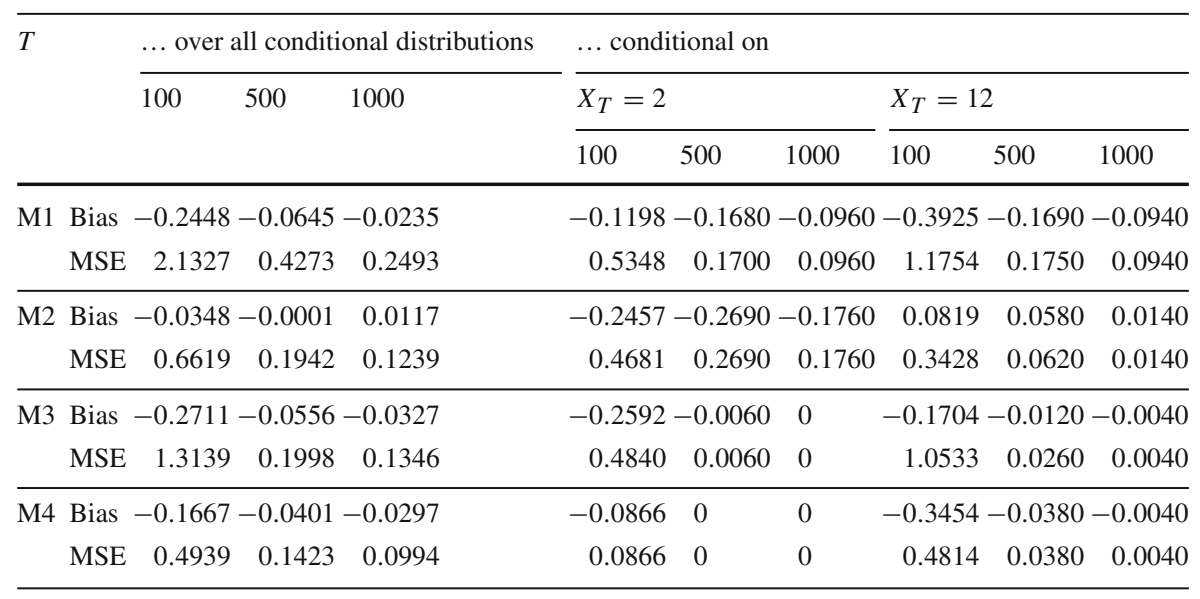

distributions converge to the stationary marginal distribution from Fig. 2, as expected from the ergodicity of the process.

To assess the accuracy of the probabilistic forecasting in the case of estimated parameters, we use an approach suggested by Corradi and Swanson (2006), which measures accuracy using a distributional analog of mean squared error. Focussing on the one-step-ahead forecast distribution, i.e., $h=1$, we denote the conditional distribution $P\left(X_{T+1}=i \mid X_{T}=j\right)$ by $f_{i \mid j}$ with $i, j \in 0,1, \ldots, N$. Then, the mean squared error of the estimator $\hat{f}_{\cdot \mid j}$ for the predictive distribution $f_{\cdot \mid j}$ is the average over the support $i \in\{0,1, \ldots, N\}$ of $E\left[\left(\hat{f}_{i \mid j}-f_{i \mid j}\right)^{2}\right]$ (note that the bias $\frac{1}{N+1} \sum_{i=0}^{N} E\left(\hat{f}_{i \mid j}-f_{i \mid j}\right)$ across the full support is equal to 0 since both the estimated and true forecast distribution sum up to 1 ). We computed the accuracy of the predictive distributions based on finite-sample paths for the models M1 to M4 from Sect. 3.1. It turned out that the distributional "MSE," as estimated from 1000 sample paths for each of the models, is negligible. To further assess the accuracy of the forecasting distribution, "Bias" and "MSE" of the median of the forecasting distributions $\hat{f}_{\cdot \mid j}$ are averaged over all $X_{T}=j$, see Table 1 . There, we also show the results for two particular cases concerning the distributions conditioned on $X_{T}=2$ (observation in lower regime) and $X_{T}=12$ (upper regime), respectively. The results presented in Table 1 indicate that the estimated median is slightly negatively biased, but both the bias and the MSE generally decrease when the sample size increases.

\section{Data example: measles in Germany in 2004-2005}

We consider again the time series of measles infections in Germany in 2004 and 2005, see Sect. 1 . We have $T=105$ data points and $N=38$ districts. A plot of the data is already shown in Fig. 1 . The observed data have an empirical mean of $\bar{x} \approx 3.305$, an empirical variance of $s^{2} \approx 6.137$ and a binomial index of dispersion of $\widehat{\mathrm{BID}} \approx 2.034$. 


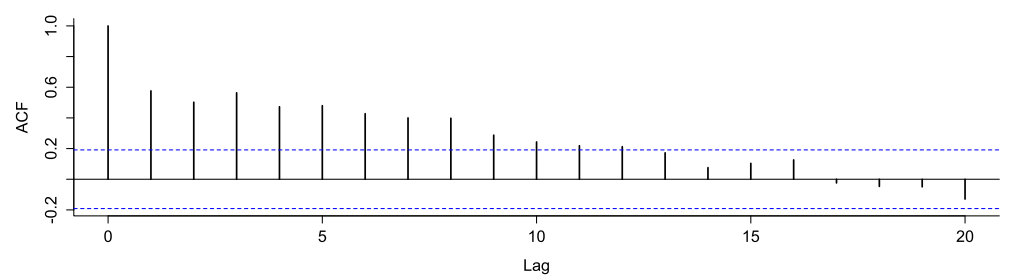

Fig. 7 Plot of SACF for measles data (2004-2005)

Table 2 Comparison of the LSET's CML estimates for different threshold values

Standard errors are given in parentheses

\begin{tabular}{lllll}
\hline$R$ & $r$ & $\pi_{1}$ & $\pi_{2}$ & $-\ell_{\max }$ \\
\hline 3 & 0.2546 & 0.0681 & 0.1174 & 217.62 \\
& $(0.0907)$ & $(0.0074)$ & $(0.0114)$ & \\
4 & 0.2245 & 0.0697 & 0.1376 & 215.05 \\
& $(0.0906)$ & $(0.0063)$ & $(0.0142)$ & \\
5 & 0.1947 & 0.0707 & 0.1604 & 212.28 \\
& $(0.0876)$ & $(0.0057)$ & $(0.0169)$ & \\
6 & 0.3083 & 0.0787 & 0.1482 & 218.24 \\
& $(0.0744)$ & $(0.0065)$ & $(0.0229)$ & \\
7 & 0.3381 & 0.0813 & 0.1594 & 218.81 \\
& $(0.0679)$ & $(0.0066)$ & $(0.0299)$ & \\
\hline
\end{tabular}

We have tested for overdispersion by using the approach of Weiß and Kim (2014) and found that the data are significantly overdispersed on a $5 \%$ level. The plot of the sample ACF (SACF) in Fig. 7 shows a slowly decaying extend of serial dependence.

In view of the level shift being visible in Fig. 1, we start with fitting an LSET model to the data (later, we also consider the more general SET model and the more special LSET $^{0}$ model). We estimate the model parameters for threshold values of $R \in\{3, \ldots, 7\}$, which is a reasonable range when we take a look at the plot of the data in Fig. 1. The estimates given different threshold values $R$ are compared in Table 2 . Looking at $-\ell_{\max }$, we decide to consider a model with a threshold value of $R=5$, also see Fig. 1. The initial values for the CML estimation procedure were obtained from the CLS estimates computed for threshold values of $R \in\{3, \ldots, 7\}$. The threshold value that minimizes $Q(\boldsymbol{\theta})$ from Eq. (20) is also $R=5$, and the corresponding CLS estimates are $\hat{r}=0.28, \hat{\pi}_{1}=0.06$ and $\hat{\pi}_{2}=0.15$.

We also applied the LR test of Sect. 3.2 to check whether such a nonlinear model is appropriate for the data. For the LSET-BAR(1) model against the BAR(1) model by McKenzie (1985) (also see Table 4 below), we obtain a value about 19.6 for the LR test statistic, while our critical value on a $5 \%$ level is given by $\chi_{1 ; 0.95}^{2}=3.841$. So we have to reject the null hypothesis of a BAR(1) model. In order to verify the applicability of the LR test from Sect. 3.2 for this data example, we simulated $n=1000$ paths of the BAR(1) model with the estimated parameters from Table 4 for different time series length $T=100,500,1000$ (with $T=100$ being close to our data). We calculated the test statistic for the SET- and LSET-BAR(1) model and studied, among others, the size 
Table 3 Simulated sizes concerning the critical values $\chi_{2,0.95}^{2}$ (SET-BAR(1) model) and $\chi_{1,0.95}^{2}$ (LSET-BAR(1) model), respectively

\begin{tabular}{llll}
\hline & $T=100$ & $T=500$ & $T=1000$ \\
\hline SET-BAR(1) & 0.053 & 0.049 & 0.049 \\
LSET-BAR(1) & 0.045 & 0.043 & 0.048 \\
\hline
\end{tabular}

Table 4 Comparison of estimated parameters (standard errors in parentheses) for different models for measles data

\begin{tabular}{|c|c|c|c|c|c|c|}
\hline & Par. 1 & Par. 2 & Par. 3 & Par. 4 & AIC & $\mathrm{BIC}$ \\
\hline $\operatorname{BAR}(1)$ & 0.0882 & 0.4158 & - & - & 448.2 & 453.5 \\
\hline$(\pi, r)$ & $(0.0070)$ & $(0.0550)$ & & & & \\
\hline DD-BAR(1) & 0.0419 & 0.5270 & 0 & - & 436.9 & 444.9 \\
\hline$(a, b, r)$ & $(0.0095)$ & (0.1077) & $(0.1765)$ & & & \\
\hline Bin. INARCH(1) & 0.0419 & 0.5270 & - & - & 434.9 & 440.2 \\
\hline$(a, b)$ & $(0.0060)$ & $(0.0682)$ & & & & \\
\hline SET-BAR(1) & 0.0706 & 0.1558 & 0.1916 & 0.2904 & 432.5 & 443.1 \\
\hline$\left(\pi_{1}, \pi_{2}, r_{1}, r_{2}\right)$ & $(0.0056)$ & $(0.0269)$ & $(0.0884)$ & $(0.375)$ & & \\
\hline LSET-BAR(1) & 0.0707 & 0.1604 & 0.1947 & - & 430.6 & 438.5 \\
\hline$\left(\pi_{1}, \pi_{2}, r\right)$ & $(0.0057)$ & $(0.0169)$ & $(0.0876)$ & & & \\
\hline $\mathrm{LSET}^{0}-\mathrm{BAR}(1)$ & 0.0689 & 0.1671 & - & - & 433.4 & 438.7 \\
\hline$\left(\pi_{1}, \pi_{2}\right)$ & $(0.0045)$ & $(0.0135)$ & & & & \\
\hline
\end{tabular}

All threshold models include a threshold value of $R=5$

if using a critical value from the asymptotic $\chi^{2}$ distribution (again nominal level $5 \%$ ). The results in Table 3 show a good agreement already for time series length $T=100$. Furthermore, none of the simulated test statistic values reached the value of the test statistic from the measles data example, which also confirms the rejection of the null hypothesis.

Next, we compare different integer-valued models with a finite range. Besides the threshold models introduced in this paper as well as the simple BAR(1) model (also remember the above LR test), we consider the following models: the above-mentioned DD-BAR(1) model as well as its boundary case, the binomial INARCH(1) model (Weiß and Pollett 2014, Section 4). Table 4 shows the comparison of the fitted models for the given data example. All estimates of the LSET-BAR(1) model are significant regarding the approximated standard errors, while for the full SET model, $r_{2}$ is not significant. Similarly, for the full DD model, $r$ is not significant, which implies to prefer its boundary case INARCH(1). Overall, however, the LSET-BAR(1) model has the lowest AIC and BIC of all models and is the model of choice considering these information criteria.

The difference between the models becomes clear through Fig. 8. The dotted straight line represents the conditional mean of the BAR(1) model against the previous observation $x_{t-1}$, which is a linear function. The dashed straight lines represent the conditional mean of the $\mathrm{LSET}^{0}$-BAR(1) model, which is piecewise constant in the regimes, see (12). The remaining solid straight lines refer 


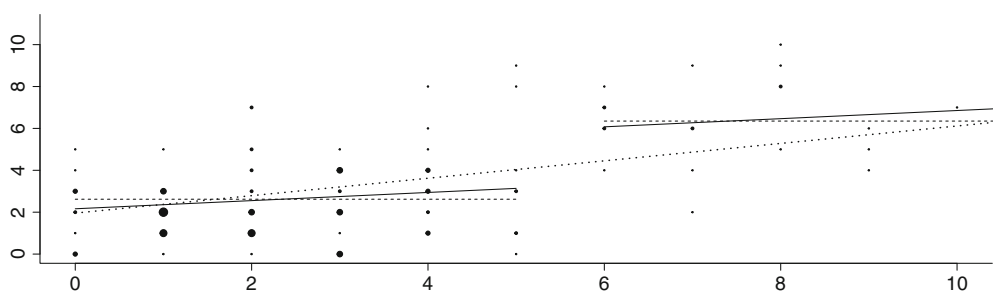

Fig. 8 Dots represent observed frequencies for measles data with coordinates $\left(x_{t-1}, x_{t}\right)$. Lines represent conditional means for BAR(1) (dotted), LSET-BAR(1) (solid) and LSET ${ }^{0}$-BAR(1) (dashed)
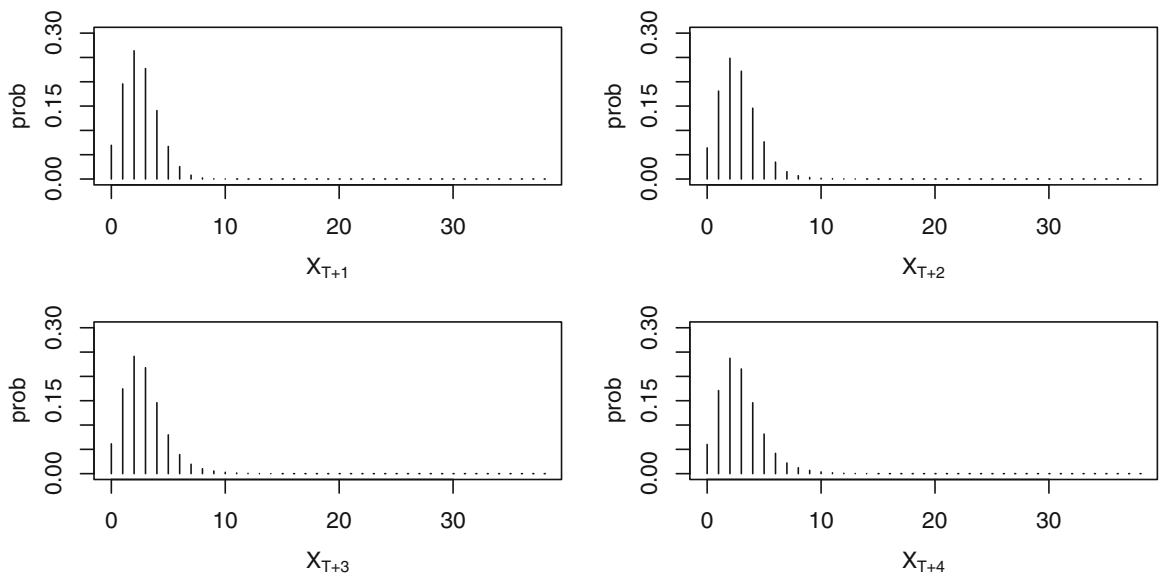

Fig. 9 Forecast distribution for 1, 2, 3 and 4 weeks ahead, conditioned on $x_{105}=2$, for the number of districts with new measles infections

to the LSET-BAR(1) model and show a piecewise linear behavior with a unique slope in both regimes. The conditional means of the DD-BAR(1) and the binomial INARCH(1) model as well as that of the SET-BAR(1) model are not shown in Fig. 8, since they are very similar to the ones of the BAR(1) or LSET-BAR(1) model, respectively. If comparing the plotted conditional means with the observed bivariate frequencies for $\left(x_{t-1}, x_{t}\right)$, the piecewise approaches seem more appropriate since the frequencies concentrate either in the lower left or in upper right quarter.

An important application of the fitted LSET model would be forecasting. The forecast distributions up to 4 weeks ahead, based on the fitted LSET model, are represented in Fig. 9 and convey information that is important for public health monitoring. For example, we can say that, conditional on the last observed value $x_{105}=2$ (infections observed in two districts), we observe infections in $\geq 6$ districts (upper regime) in the following week with a probability around $3.7 \%$. With increasing forecast horizon, this conditional probability increases up to about $11.0 \%$. We also applied the one-step-ahead forecast distributions to the measles data itself, see Fig. 1, where the limits of the $95 \%$ prediction intervals are shown. Only two observations lie outside these intervals, which adapt nicely to the level shift in the data. For the BAR(1)- 


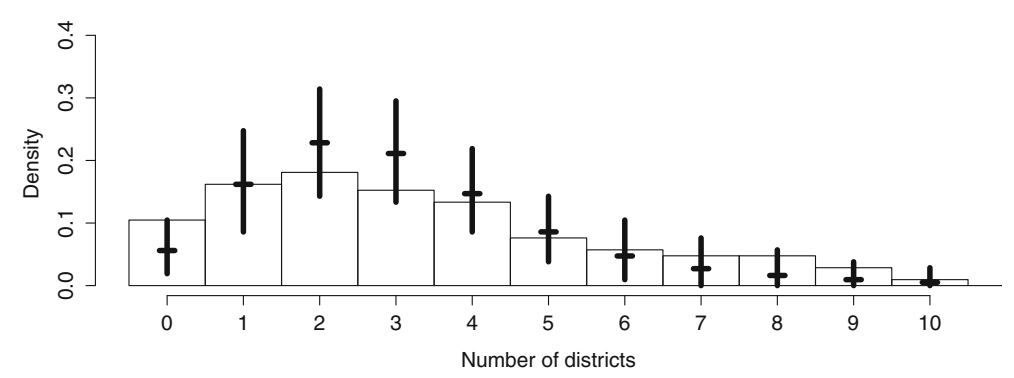

Fig. 10 Comparison of histogram of measles data (bars) and marginal distribution of fitted LSET model (ticks). 95\% confidence bands from parametric bootstrap (black lines)

based forecasts instead (not shown), the $95 \%$ bands look clearly worse, which again confirms preferring the LSET model for our measles data. Generally, if looking at the coverage rates of the one-step-ahead prediction intervals for different levels, the BAR(1) model always performs worst, and the $\mathrm{LSET}^{0}$ model is second worst, while all remaining models do comparably well in terms of this retrospective forecasting.

At this point, it is also interesting to look at a completely different approach toward modeling the piecewise behavior. As already pointed out in Sect. 1, a parameter-driven alternative would be a (two-state) binomial HMM (Zucchini and MacDonald 2009). Although the estimates for the HMM's transition matrix are not significant, there are well-interpretable analogies between the fitted HMM and the LSET-BAR(1) model. The estimated binomial parameters of the HMM are 0.0590 in the lower and 0.1740 in the upper regime, which are fairly close to the estimates for $\pi_{1}, \pi_{2}$ in the LSET-BAR(1) model, the latter being 0.0707, 0.1604. The stationary distribution in the HMM gives us a probability of 0.8132 to be in the lower regime, while the LSET-BAR(1) model results in $p=0.8905$. So both types of regime switching model lead to similar conclusions with respect to the measles data.

Although the LSET model performs best among all candidate models, it does not perfectly describe the measles data. While the mean within the fitted LSET model is close to the empirically observed one (3.060 vs. 3.305), its BID is visibly smaller than the empirically observed one (1.440 vs. 2.034). So the fitted LSET model is not able to reflect the full extend of observed overdispersion, which also becomes clear by looking at Fig. 10, where the LSET's marginal distribution (together with $95 \%$ confidence bands from a parametric bootstrap) is plotted against a histogram of the data. Although confidence bands and histogram always overlap, the LSET's distribution is stronger centered around values from 1 to 4. Another weakness of the fitted LSET model is that its ACF does not fit the SACF of the measles data particularly well, see Fig. 11. This issue motivates to discuss possible extensions of our basic SET models in the following section, where we shall see that a higher delay parameter solves the ACF problem. 

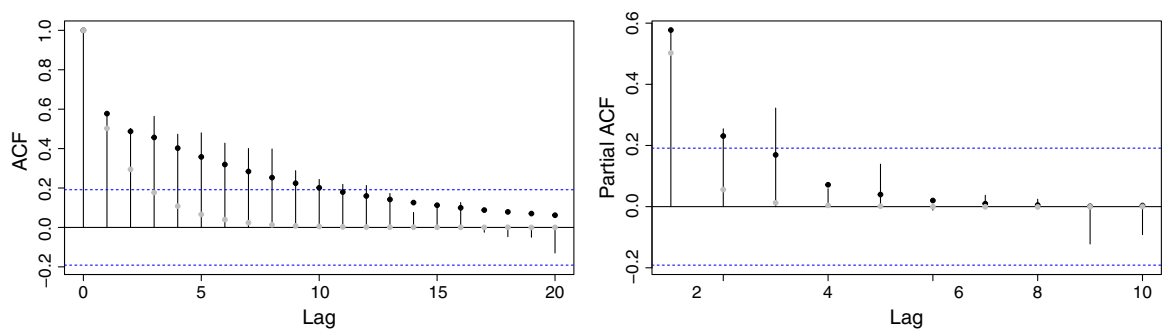

Fig. 11 SACF and SPACF of measles data (bars) compared to estimated higher delay model (black dots) and to estimated LSET-BAR(1) model from Table 4 (gray dots)

\section{Possible extensions of the SET-BAR(1) model}

\subsection{Multiple regimes or higher-order dependence}

The SET-BAR(1) model according to Definition 2.1 is a basic first-order model with two regimes and with delay parameter 1 . Depending on the concrete application, it can be extended in several ways. First, more than two regimes are easily possible, e.g., by dividing the range into $k>2$ partitions of the form $\left\{0, \ldots, R_{1}\right\},\left\{R_{1}+\right.$ $\left.1, \ldots, R_{2}\right\}, \ldots,\left\{R_{k-1}+1, \ldots, N\right\}$ with $0 \leq R_{1}<\cdots<R_{k-1}<N$, with an individual set of parameters $\left(\pi_{1}, r_{1}\right), \ldots,\left(\pi_{k}, r_{k}\right)$ for each regime. But since the finite range will be quite small in many real data scenarios, the choice of only two regimes will often be reasonable. Secondly, our approaches could be extended to higher-order autoregressions by adapting the binomial $\operatorname{AR}(p)$ model of Weiß (2009), thus leading to a $p$ th-order Markov process (at the price of an increased number of parameters). Here, we shall discuss a third possibility in some more detail, an extension of the simple SET-BAR(1) model with a higher delay $d>1$ by considering $\mathbb{1}_{\left\{X_{t-d} \leq R\right\}}$ as the condition for switching between the regimes, also see the analogous discussion in Tong (2011). This extension comes along with the definition of more complex threshold conditions, and it does not require additional parameters. Also here, the Markov property is preserved (now $d$ th-order Markov process), which is helpful for parameter estimation and forecasting.

For delays $d>1$, one may simply shift the threshold condition in time, leading to $X_{t-d} \leq R$. But a larger delay can also be combined with some function on the last $d$ observations, i.e., the threshold condition becomes $f\left(X_{t-d}, \ldots, X_{t-1}\right) \leq \tilde{R}$. For example, the function $f$ could be the mean of the past $d$ observations, in analogy to Thyregod et al. (1999). Of course, it may happen that $f\left(X_{t-d}, \ldots, X_{t-1}\right)$ attains values outside the range $\{0, \ldots, N\}$, so we have to choose the threshold value $\tilde{R}$ in an appropriate way. If, as another example, $f$ returns the minimum of $X_{t-d}, \ldots, X_{t-1}$, then at least one of the observations has to be not larger than $\tilde{R}$.

For the measles data, we finally decided to discriminate the regimes in the following way: The process is in the lower regime if $\max \left\{X_{t-3}, X_{t-2}, X_{t-1}\right\} \leq 5$, and in the upper regime otherwise. Note that the max condition is equivalent to requiring that all values $X_{t-3}, X_{t-2}, X_{t-1} \leq 5$. The results for the ACF and partial ACF (PACF) of this extended model, compared to the LSET-BAR(1) model, are shown in Fig. 11. 
Obviously, we achieve a much better fit to both SACF and SPACF by this threshold condition, and the new model shows a much longer memory. Furthermore, mean (3.49), variance (5.83) and BID (1.84) of this model better agree with the empirically observed values for the measles data.

\subsection{A bivariate extension}

The SET-BAR(1) process can also be generalized to the case of multivariate observations. A possible extension is to induce piecewise-type patterns to the class of bivariate binomial autoregressive models introduced by Scotto et al. (2014), which are based on the bivariate binomial thinning operator " $\otimes$," defined via

$$
\left(\alpha_{1}, \alpha_{2}, \varphi_{\alpha}\right) \otimes \mathbf{X} \mid \mathbf{X} \sim \operatorname{BVB}_{\mathrm{II}}\left(X_{1}, X_{2}, \min \left\{X_{1}, X_{2}\right\} ; \alpha_{1}, \alpha_{2}, \varphi_{\alpha}\right)
$$

The definition of the SET-BVB $\mathrm{II}-\mathrm{AR}(1)$ is given below.

Definition 6.1 Let $N:=\left[\begin{array}{ll}N_{1} & N_{2}\end{array}\right]^{\prime} \in \mathbb{N}^{2}$ be the vector of upper limits for the bivariate range, let $0 \leq R_{j}<N_{j}$ for $j \in\{1,2\}$ be the threshold values.

For $i \in\{0,1\}^{2}$ and $j \in\{1,2\}$, let $\pi_{j}^{(i)} \in(0 ; 1)$, and

$$
r_{j}^{(i)} \in\left(\max \left\{-\frac{\pi_{j}^{(i)}}{1-\pi^{(i)}},-\frac{1-\pi_{j}^{(i)}}{\pi_{j}^{(i)}}\right\} ; 1\right) .
$$

In addition, define $\beta_{j}^{(i)}:=\pi_{j}^{(i)} \cdot\left(1-r_{j}^{(i)}\right) \in(0 ; 1)$ and $\alpha_{j}^{(i)}:=\beta_{j}^{(i)}+r_{j}^{(i)} \in(0 ; 1)$. Let $\boldsymbol{\alpha}^{(i)}:=\left(\alpha_{1}^{(i)}, \alpha_{2}^{(i)}, \varphi_{\alpha}^{(i)}\right)$ and $\boldsymbol{\beta}^{(i)}:=\left(\beta_{1}^{(i)}, \beta_{2}^{(i)}, \varphi_{\beta}^{(i)}\right)$.

The process $\left(\mathbf{X}_{t}\right)$ of bivariate random variables $\mathbf{X}_{t}:=\left[\begin{array}{lll}X_{t, 1} & X_{t, 2}\end{array}\right]^{\prime}$ is called SET-BVB II $-\mathrm{AR}(1)$ if $\mathbf{X}_{t}$ satisfies the recursion

$$
\mathbf{X}_{t}=\boldsymbol{\phi}_{t} \otimes \mathbf{X}_{t-1}+\boldsymbol{\eta}_{t} \otimes\left(N-\mathbf{X}_{t-1}\right) \text { for } t \in \mathbb{Z}
$$

where $\boldsymbol{\phi}_{t}:=\boldsymbol{\alpha}^{\left(\boldsymbol{I}_{t-1}\right)}, \boldsymbol{\eta}_{t}:=\boldsymbol{\beta}^{\left(\boldsymbol{I}_{t-1}\right)}$, and $\boldsymbol{I}_{t-1}:=\left[\mathbb{1}_{\left\{X_{t-1,1}>R_{1}\right\}} \mathbb{1}_{\left\{X_{t-1,2}>R_{2}\right\}}\right]^{\prime}$.

Furthermore, it is assumed that the thinnings are performed independently of each other.

So the bivariate indicator $\boldsymbol{I}_{t-1}$ distinguishes between the following events:

$$
\begin{array}{ll}
\boldsymbol{I}_{t-1}=\left[\begin{array}{ll}
0 & 0
\end{array}\right]^{\prime} & \text { iff }\left\{X_{t-1,1} \leq R_{1}, X_{t-1,2} \leq R_{2}\right\} \\
\boldsymbol{I}_{t-1}=\left[\begin{array}{ll}
0 & 1
\end{array}\right]^{\prime} & \text { iff }\left\{X_{t-1,1} \leq R_{1}, X_{t-1,2}>R_{2}\right\} ; \\
\boldsymbol{I}_{t-1}=\left[\begin{array}{ll}
1 & 0
\end{array}\right]^{\prime} & \text { iff }\left\{X_{t-1,1}>R_{1}, X_{t-1,2} \leq R_{2}\right\} ; \\
\boldsymbol{I}_{t-1}=\left[\begin{array}{ll}
1 & 1
\end{array}\right]^{\prime} & \text { iff }\left\{X_{t-1,1}>R_{1}, X_{t-1,2}>R_{2}\right\} .
\end{array}
$$

The transition probabilities at lag 1 of the SET-BVB II $^{-A R}(1)$ model are computed through the expression 


$$
\begin{aligned}
p_{\boldsymbol{k} \mid \boldsymbol{l}} & :=P\left(\mathbf{X}_{t}=\boldsymbol{k} \mid \mathbf{X}_{t-1}=\boldsymbol{l}\right) \equiv P\left(\boldsymbol{\phi}_{t} \otimes \mathbf{X}_{t-1}+\eta_{t} \otimes\left(\boldsymbol{N}-\mathbf{X}_{t-1}\right)=\boldsymbol{k} \mid \mathbf{X}_{t-1}=\boldsymbol{l}\right) \\
& =\sum_{a_{1}=0}^{\min \left\{k_{1}, l_{1}\right\}} \sum_{a_{2}=0}^{\min \left\{k_{2}, l_{2}\right\}} p_{\left(l_{1}, l_{2} ; \boldsymbol{\alpha}^{(i)}\right)}\left(a_{1}, a_{2}\right) p_{\left(N_{1}-l_{1}, N_{2}-l_{2} ; \boldsymbol{\beta}^{(i)}\right)}\left(k_{1}-a_{1}, k_{2}-a_{2}\right),
\end{aligned}
$$

where $\boldsymbol{k}:=\left[\begin{array}{ll}k_{1} & k_{2}\end{array}\right]^{\prime}, \boldsymbol{l}:=\left[\begin{array}{ll}l_{1} & 1_{2}\end{array}\right]^{\prime}$ as well as $\boldsymbol{i}:=\left[\begin{array}{ll}\mathbb{1}_{\left\{l_{1}>R_{1}\right\}} & \mathbb{1}_{\left\{l_{2}>R_{2}\right\}}\end{array}\right]^{\prime}$, and where the bivariate probability mass functions $p_{(\cdot)}(\cdot)$ defined as in equation (13) in Scotto et al. (2014, p. 236). Note that since these transition probabilities are truly positive, the SET-BVB $\mathrm{II}_{\mathrm{I}} \mathrm{AR}(1)$ process is a primitive and finite-state Markov chain, which, in turn, implies irreducibility and aperiodicity. Hence, a uniquely determined stationary marginal distribution exists. Denoting the transition matrix by $\mathbf{P}:=\left(p_{\boldsymbol{k} \mid l}\right)$, the unique stationary marginal distribution, expressed as a vector $\boldsymbol{p}$, is obtained as the solution of the linear equation $\mathbf{P} \boldsymbol{p}=\boldsymbol{p}$.

Now we are prepared to obtain the mean, the variance and the autocovariance function of the process. For simplicity in notation, we define $q_{i}:=P\left(\boldsymbol{I}_{t-1}=\boldsymbol{i}\right)$ and $u_{j, i}:=E\left[X_{t-1, j} \mid \boldsymbol{I}_{t-1}=\boldsymbol{i}\right], \sigma_{j, i}^{2}:=V\left[X_{t-1, j} \mid \boldsymbol{I}_{t-1}=\boldsymbol{i}\right]$ for $\boldsymbol{i} \in\{0,1\}^{2}$ and $j \in\{1,2\}$. The mean of the process is given by

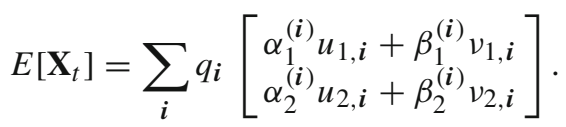

In order to calculate the variance (componentwise), note first that

$$
\begin{aligned}
V\left[\mathbf{X}_{t}\right]= & V\left[\boldsymbol{\phi}_{t} \otimes \mathbf{X}_{t-1}+\eta_{t} \otimes\left(N-\mathbf{X}_{t-1}\right)\right] \\
= & V\left[\boldsymbol{\phi}_{t} \otimes \mathbf{X}_{t-1}\right]+V\left[\boldsymbol{\eta}_{t} \otimes\left(\boldsymbol{N}-\mathbf{X}_{t-1}\right)\right] \\
& +2 \operatorname{Cov}\left[\boldsymbol{\phi}_{t} \otimes \mathbf{X}_{t-1}, \boldsymbol{\eta}_{t} \otimes\left(\boldsymbol{N}-\mathbf{X}_{t-1}\right)\right] \\
= & : \mathrm{I}+\mathrm{II}+\text { III. }
\end{aligned}
$$

The term I can be obtained through the expression

$$
\begin{aligned}
\mathrm{I} & =V\left[E\left(\boldsymbol{\phi}_{t} \otimes \mathbf{X}_{t-1} \mid \mathbf{X}_{t-1}\right)\right]+E\left[V\left(\boldsymbol{\phi}_{t} \otimes \mathbf{X}_{t-1} \mid \mathbf{X}_{t-1}\right)\right] \\
& =\sum_{\boldsymbol{i}} q_{i}\left[\begin{array}{c}
\left(\alpha_{1}^{(i)}\right)^{2} \sigma_{1, i}^{2}+\alpha_{1}^{(i)}\left(1-\alpha_{1}^{(i)}\right) u_{1, i} \\
\left(\alpha_{2}^{(i)}\right)^{2} \sigma_{2, i}^{2}+\alpha_{2}^{(i)}\left(1-\alpha_{2}^{(i)}\right) u_{2, i}
\end{array}\right] .
\end{aligned}
$$

By similar arguments, it follows that

$$
\mathrm{II}=\sum_{i} q_{i}\left[\begin{array}{c}
\beta_{1}^{(i)^{2}} \sigma_{1, i}^{2}+\beta_{1}^{(i)}\left(1-\beta_{1}^{(i)}\right)\left(N_{1}-u_{1, i}\right) \\
\beta_{2}^{(i)^{2}} \sigma_{2, i}^{2}+\beta_{2}^{(i)}\left(1-\beta_{2}^{(i)}\right)\left(N_{2}-u_{2, i}\right)
\end{array}\right] .
$$


Finally, to obtain III, note that

$$
\begin{aligned}
\operatorname{Cov} & {\left[\left(\boldsymbol{\phi}_{t} \otimes \mathbf{X}_{t-1}\right)_{j},\left(\boldsymbol{\eta}_{t} \otimes\left(\boldsymbol{N}-\mathbf{X}_{t-1}\right)\right)_{j}\right] } \\
& =\sum_{i} q_{i} \operatorname{Cov}\left[\left(\alpha^{(i)} \otimes \mathbf{X}_{t-1}\right)_{j},\left(\beta^{(i)} \otimes\left(\boldsymbol{N}-\mathbf{X}_{t-1}\right)\right)_{j} \mid \boldsymbol{I}_{t-1}=\boldsymbol{i}\right] \\
& =-\sum_{i} q_{i} \alpha_{j}^{(i)} \beta_{j}^{(i)} \operatorname{Cov}\left[X_{t-1, j}, X_{t-1, j} \mid \boldsymbol{I}_{t-1}=\boldsymbol{i}\right] .
\end{aligned}
$$

To calculate the cross-covariance function, we proceed as follows:

$$
\begin{aligned}
\operatorname{Cov}\left[X_{t, 1}, X_{t, 2}\right]= & \operatorname{Cov}\left[\left(\boldsymbol{\phi}_{t} \otimes \mathbf{X}_{t-1}\right)_{1},\left(\boldsymbol{\phi}_{t} \otimes \mathbf{X}_{t-1}\right)_{2}\right] \\
& +\operatorname{Cov}\left[\left(\boldsymbol{\eta}_{t} \otimes\left(\boldsymbol{N}-\mathbf{X}_{t-1}\right)\right)_{1},\left(\boldsymbol{\eta}_{t} \otimes\left(\boldsymbol{N}-\mathbf{X}_{t-1}\right)\right)_{2}\right] \\
& +\operatorname{Cov}\left[\left(\boldsymbol{\phi}_{t} \otimes \mathbf{X}_{t-1}\right)_{1},\left(\boldsymbol{\eta}_{t} \otimes\left(\boldsymbol{N}-\mathbf{X}_{t-1}\right)\right)_{2}\right] \\
& +\operatorname{Cov}\left[\left(\boldsymbol{\eta}_{t} \otimes\left(\boldsymbol{N}-\mathbf{X}_{t-1}\right)\right)_{1},\left(\boldsymbol{\phi}_{t} \otimes \mathbf{X}_{t-1}\right)_{2}\right] \\
= & \mathrm{I}+\mathrm{II}+\mathrm{III}+\mathrm{IV} .
\end{aligned}
$$

Straightforward (although tedious) algebraic calculations lead to

$$
\begin{aligned}
\mathrm{I}+\mathrm{II}=\sum_{\boldsymbol{i}} q_{\boldsymbol{i}} \cdot\left[\left(\alpha_{1}^{(\boldsymbol{i})} \alpha_{2}^{(\boldsymbol{i})}+\beta_{1}^{(\boldsymbol{i})} \beta_{2}^{(i)}\right) \cdot \operatorname{Cov}\left[X_{t-1,1}, X_{t-1,2} \mid \boldsymbol{I}_{t-1}=\boldsymbol{i}\right]\right. \\
+\varphi_{\alpha}^{(\boldsymbol{i})} \cdot \sqrt{\alpha_{1}^{(\boldsymbol{i})} \alpha_{2}^{(\boldsymbol{i})}\left(1-\alpha_{1}^{(i)}\right)\left(1-\alpha_{2}^{(i)}\right)} \cdot E\left[\min \left\{X_{t-1,1}, X_{t-1,2}\right\} \mid \boldsymbol{I}_{t-1}=\boldsymbol{i}\right] \\
+\varphi_{\beta}^{(i)} \cdot \sqrt{\beta_{1}^{(i)} \beta_{2}^{(i)}\left(1-\beta_{1}^{(i)}\right)\left(1-\beta_{2}^{(i)}\right)} \\
\left.\quad \cdot E\left[\min \left\{N_{1}-X_{t-1,1}, N_{2}-X_{t-1,2}\right\} \mid \boldsymbol{I}_{t-1}=\boldsymbol{i}\right]\right] .
\end{aligned}
$$

Similarly,

$$
\mathrm{III}+\mathrm{IV}=-\sum_{i} q_{i}\left(\alpha_{1}^{(i)} \beta_{2}^{(i)}+\alpha_{2}^{(i)} \beta_{1}^{(i)}\right) \cdot \operatorname{Cov}\left[X_{t-1,1}, X_{t-1,2} \mid \boldsymbol{I}_{t-1}=i\right]
$$

and one concludes in analogy to Theorem 5.2 in Scotto et al. (2014).

\section{Concluding remarks}

In this paper, we proposed types of self-exciting threshold models for integer-valued time series with a finite range, which are based on the BAR(1) model by McKenzie (1985). We analyzed their marginal means and variances as well as further stochastic properties, and we considered the topic of forecasting as an application. For estimation purposes, we considered the conditional least squares and the maximum likelihood approach, and we investigated both their asymptotic and finite-sample behavior. We successfully applied the novel self-exciting threshold models to a case study of measles 
infections in Germany. Finally, we exemplified the potential for further generalizing our models by proposing a model with a higher delay as well as a bivariate extension.

Acknowledgments The authors thank the referees for carefully reading the article and for their comments, which greatly improved the article. This work was supported by Portuguese funds through the CIDMA-Center for Research and Development in Mathematics and Applications, and the Portuguese Foundation for Science and Technology (FCT-Fundação para a Ciência e a Tecnologia), within project UID/MAT/04106/2013.

\section{Appendix 1: Proofs}

\section{Unconditional mean and variance}

The unconditional mean (6) is a direct consequence of (4):

$$
\begin{aligned}
\mu_{X}= & E\left[E\left[X_{t} \mid X_{t-1}\right]\right]=r_{1} \mu_{I X}+\left(1-r_{1}\right) \pi_{1} N p+r_{2}\left(\mu_{X}-\mu_{I X}\right) \\
& +\left(1-r_{2}\right) \pi_{2} N(1-p) \\
= & r_{2} \mu_{X}+\left(r_{1}-r_{2}\right) \mu_{I X}+N p \pi_{1}\left(1-r_{1}\right)+N(1-p) \pi_{2}\left(1-r_{2}\right) .
\end{aligned}
$$

For the unconditional variance (7), consider first

$$
\begin{aligned}
E[ & \left.V\left[X_{t} \mid X_{t-1}\right]\right] \\
& \stackrel{(5)}{=} E\left[I_{t-1}\left(r_{1}\left(1-r_{1}\right)\left(1-2 \pi_{1}\right) X_{t-1}+N\left(1-r_{1}\right) \pi_{1}\left(1-\left(1-r_{1}\right) \pi_{1}\right)\right)\right] \\
& +E\left[\left(1-I_{t-1}\right)\left(r_{2}\left(1-r_{2}\right)\left(1-2 \pi_{2}\right) X_{t-1}+N\left(1-r_{2}\right) \pi_{2}\left(1-\left(1-r_{2}\right) \pi_{2}\right)\right)\right] \\
= & r_{1}\left(1-r_{1}\right)\left(1-2 \pi_{1}\right) \mu_{I X}+p N\left(1-r_{1}\right) \pi_{1}\left(1-\left(1-r_{1}\right) \pi_{1}\right) \\
& +r_{2}\left(1-r_{2}\right)\left(1-2 \pi_{2}\right)\left(\mu_{X}-\mu_{I X}\right)+(1-p) N\left(1-r_{2}\right) \pi_{2}\left(1-\left(1-r_{2}\right) \pi_{2}\right),
\end{aligned}
$$

as well as (note that $\left.E\left[I_{t-1}\left(1-I_{t-1}\right) \cdot Y\right]=0\right)$

$$
\begin{aligned}
V[ & \left.E\left[X_{t} \mid X_{t-1}\right]\right] \stackrel{(4)}{=} V\left[I_{t-1}\left(r_{1} X_{t-1}+\left(1-r_{1}\right) \pi_{1} N\right)\right. \\
& \left.+\left(1-I_{t-1}\right)\left(r_{2} X_{t-1}+\left(1-r_{2}\right) \pi_{2} N\right)\right] \\
= & V\left[I_{t-1}\left(r_{1} X_{t-1}+\left(1-r_{1}\right) \pi_{1} N\right)\right]+V\left[\left(1-I_{t-1}\right)\left(r_{2} X_{t-1}+\left(1-r_{2}\right) \pi_{2} N\right)\right] \\
& +2 \operatorname{Cov}\left[I_{t-1}\left(r_{1} X_{t-1}+\left(1-r_{1}\right) \pi_{1} N\right),\left(1-I_{t-1}\right)\left(r_{2} X_{t-1}+\left(1-r_{2}\right) \pi_{2} N\right)\right] \\
= & V\left[I_{t-1} r_{1} X_{t-1}\right]+V\left[I_{t-1}\left(1-r_{1}\right) \pi_{1} N\right] \\
& +2 \operatorname{Cov}\left[I_{t-1} r_{1} X_{t-1}, I_{t-1}\left(1-r_{1}\right) \pi_{1} N\right] \\
& +V\left[\left(1-I_{t-1}\right) r_{2} X_{t-1}\right]+V\left[\left(1-I_{t-1}\right)\left(1-r_{2}\right) \pi_{2} N\right] \\
& +2 \operatorname{Cov}\left[\left(1-I_{t-1}\right) r_{2} X_{t-1},\left(1-I_{t-1}\right)\left(1-r_{2}\right) \pi_{2} N\right] \\
& +0-2 E\left[I_{t-1}\left(r_{1} X_{t-1}+\left(1-r_{1}\right) \pi_{1} N\right)\right] \cdot E\left[\left(1-I_{t-1}\right)\left(r_{2} X_{t-1}+\left(1-r_{2}\right) \pi_{2} N\right)\right] \\
= & r_{1}^{2} V\left[I_{t-1} X_{t-1}\right]+\left(1-r_{1}\right)^{2} \pi_{1}^{2} N^{2} p(1-p)
\end{aligned}
$$




$$
\begin{aligned}
& +2 r_{1}\left(1-r_{1}\right) \pi_{1} N \operatorname{Cov}\left[I_{t-1} X_{t-1}, I_{t-1}\right] \\
& +r_{2}^{2} V\left[\left(1-I_{t-1}\right) X_{t-1}\right]+\left(1-r_{2}\right)^{2} \pi_{2}^{2} N^{2} p(1-p) \\
& +2 r_{2}\left(1-r_{2}\right) \pi_{2} N \operatorname{Cov}\left[\left(1-I_{t-1}\right) X_{t-1},\left(1-I_{t-1}\right)\right] \\
& -2 r_{1} r_{2} \mu_{I X}\left(\mu_{X}-\mu_{I X}\right)-2 r_{1}\left(1-r_{2}\right) \pi_{2}(1-p) N \mu_{I X} \\
& -2 r_{2}\left(1-r_{1}\right) \pi_{1} p N\left(\mu_{X}-\mu_{I X}\right)-2 p(1-p)\left(1-r_{1}\right) \pi_{1}\left(1-r_{2}\right) \pi_{2} N^{2} \\
& =r_{1}^{2}\left(\mu_{I X, 2}-\mu_{I X}^{2}\right)+\left(1-r_{1}\right)^{2} \pi_{1}^{2} N^{2} p(1-p)+2 r_{1}\left(1-r_{1}\right) \pi_{1} N(1-p) \mu_{I X} \\
& +r_{2}^{2}\left(\sigma_{X}^{2}+2 \mu_{X} \mu_{I X}-\mu_{I X, 2}-\mu_{I X}^{2}\right)+\left(1-r_{2}\right)^{2} \pi_{2}^{2} N^{2} p(1-p) \\
& +2 r_{2}\left(1-r_{2}\right) \pi_{2} N p\left(\mu_{X}-\mu_{I X}\right) \\
& -2 r_{1} r_{2} \mu_{I X}\left(\mu_{X}-\mu_{I X}\right)-2 r_{1}\left(1-r_{2}\right) \pi_{2}(1-p) N \mu_{I X} \\
& -2 r_{2}\left(1-r_{1}\right) \pi_{1} p N\left(\mu_{X}-\mu_{I X}\right)-2 p(1-p)\left(1-r_{1}\right) \pi_{1}\left(1-r_{2}\right) \pi_{2} N^{2} .
\end{aligned}
$$

Insertion of (30) and (31) into $\sigma_{X}^{2}=E\left[V\left[X_{t} \mid X_{t-1}\right]\right]+V\left[E\left[X_{t} \mid X_{t-1}\right]\right]$ and reordering gives

$$
\begin{aligned}
(1- & \left.r_{2}^{2}\right) \sigma_{X}^{2} \\
= & r_{1}\left(1-r_{1}\right)\left(1-2 \pi_{1}\right) \mu_{I X}+r_{2}\left(1-r_{2}\right)\left(1-2 \pi_{2}\right)\left(\mu_{X}-\mu_{I X}\right) \\
& +N p\left(1-r_{1}\right) \pi_{1}\left(1-\left(1-r_{1}\right) \pi_{1}\right)+N(1-p)\left(1-r_{2}\right) \pi_{2}\left(1-\left(1-r_{2}\right) \pi_{2}\right) \\
& +r_{1}^{2}\left(\mu_{I X, 2}-\mu_{I X}^{2}\right)+2 r_{2}^{2} \mu_{X} \mu_{I X}-r_{2}^{2}\left(\mu_{I X, 2}+\mu_{I X}^{2}\right)-2 r_{1} r_{2} \mu_{I X}\left(\mu_{X}-\mu_{I X}\right) \\
& +\left(1-r_{1}\right)^{2} \pi_{1}^{2} N^{2} p(1-p)+\left(1-r_{2}\right)^{2} \pi_{2}^{2} N^{2} p(1-p) \\
& -2\left(1-r_{1}\right) \pi_{1}\left(1-r_{2}\right) \pi_{2} N^{2} p(1-p) \\
& +2 r_{1}\left(1-r_{1}\right) \pi_{1} N(1-p) \mu_{I X}-2 r_{1}\left(1-r_{2}\right) \pi_{2} N(1-p) \mu_{I X} \\
& +2 r_{2}\left(1-r_{2}\right) \pi_{2} N p\left(\mu_{X}-\mu_{I X}\right)-2 r_{2}\left(1-r_{1}\right) \pi_{1} N p\left(\mu_{X}-\mu_{I X}\right) \\
= & \left(r_{1}\left(1-r_{1}\right)\left(1-2 \pi_{1}\right)-r_{2}\left(1-r_{2}\right)\left(1-2 \pi_{2}\right)\right) \mu_{I X}+r_{2}\left(1-r_{2}\right)\left(1-2 \pi_{2}\right) \mu_{X} \\
& +N p\left(1-r_{1}\right) \pi_{1}\left(1-\left(1-r_{1}\right) \pi_{1}\right)+N(1-p)\left(1-r_{2}\right) \pi_{2}\left(1-\left(1-r_{2}\right) \pi_{2}\right) \\
& +\left(r_{1}^{2}-r_{2}^{2}\right) \mu_{I X, 2}-\left(r_{1}-r_{2}\right)^{2} \mu_{I X}^{2}-2 r_{2}\left(r_{1}-r_{2}\right) \mu_{X} \mu_{I X} \\
& +N^{2} p(1-p)\left(\left(1-r_{1}\right) \pi_{1}-\left(1-r_{2}\right) \pi_{2}\right)^{2} \\
& +2 N(1-p) r_{1}\left(\left(1-r_{1}\right) \pi_{1}-\left(1-r_{2}\right) \pi_{2}\right) \mu_{I X} \\
& -2 N p r_{2}\left(\left(1-r_{1}\right) \pi_{1}-\left(1-r_{2}\right) \pi_{2}\right)\left(\mu_{X}-\mu_{I X}\right) \\
= & r_{2}\left(1-r_{2}\right)\left(1-2 \pi_{2}\right) \mu_{X}-2 N_{p}\left(\left(1-r_{1}\right) \pi_{1}-\left(1-r_{2}\right) \pi_{2}\right) \mu_{X} \\
& -2 r_{2}\left(r_{1}-r_{2}\right) \mu_{X} \mu_{I X}+\left(r_{1}^{2}-r_{2}^{2}\right) \mu_{I X, 2}-\left(r_{1}-r_{2}\right)^{2} \mu_{I X}^{2} \\
& +2 N\left(r_{1}-p\left(r_{1}-r_{2}\right)\right)\left(\left(1-r_{1}\right) \pi_{1}-\left(1-r_{2}\right) \pi_{2}\right) \mu_{I X} \\
& +\left(r_{1}\left(1-r_{1}\right)\left(1-2 \pi_{1}\right)-r_{2}\left(1-r_{2}\right)\left(1-2 \pi_{2}\right)\right) \mu_{I X} \\
& +N p\left(1-r_{1}\right) \pi_{1}\left(1-\left(1-r_{1}\right) \pi_{1}\right)+N(1-p)\left(1-r_{2}\right) \pi_{2}\left(1-\left(1-r_{2}\right) \pi_{2}\right) \\
& +N^{2} p(1-p)\left(\left(1-r_{1}\right) \pi_{1}-\left(1-r_{2}\right) \pi_{2}\right)^{2} . \\
& \left.+N^{2}\right)
\end{aligned}
$$

This completes the proof of the variance formula (7). 
To get the properties of the LSET-BAR(1) model, we have to insert $r:=r_{1}=r_{2}$ into the Eqs. (6) and (7). We start with the mean (10):

$$
(1-r) \mu_{X}=0+N p \pi_{1}(1-r)+N(1-p) \pi_{2}(1-r) .
$$

The derivation of the variance (11) is more tedious:

$$
\begin{aligned}
& \left(1-r^{2}\right) \sigma_{X}^{2} \\
& =r(1-r)\left(1-2 \pi_{2}\right) \mu_{X}+2 N p r(1-r)\left(\pi_{2}-\pi_{1}\right) \mu_{X} \\
& -2 N r(1-r)\left(\pi_{2}-\pi_{1}\right) \mu_{I X}+r(1-r)\left(\left(1-2 \pi_{1}\right)-\left(1-2 \pi_{2}\right)\right) \mu_{I X} \\
& +N p(1-r) \pi_{1}\left(1-(1-r) \pi_{1}\right)+N(1-p)(1-r) \pi_{2}\left(1-(1-r) \pi_{2}\right) \\
& +N^{2} p(1-p)(1-r)^{2}\left(\pi_{2}-\pi_{1}\right)^{2} \\
& =r(1-r)\left(1-2 \pi_{2}\right) N\left(p \pi_{1}+(1-p) \pi_{2}\right) \\
& +2 N p r(1-r)\left(\pi_{2}-\pi_{1}\right) N\left(\pi_{2}-p\left(\pi_{2}-\pi_{1}\right)\right) \\
& -2(N-1) r(1-r)\left(\pi_{2}-\pi_{1}\right) \mu_{I X}+N p\left(1-r^{2}\right) \pi_{1}\left(1-\pi_{1}\right) \\
& \text { - Npr }(1-r) \pi_{1}\left(1-2 \pi_{1}\right) \\
& +N(1-p)\left(1-r^{2}\right) \pi_{2}\left(1-\pi_{2}\right)-N(1-p) r(1-r) \pi_{2}\left(1-2 \pi_{2}\right) \\
& +N^{2} p(1-p)\left(1-r^{2}\right)\left(\pi_{2}-\pi_{1}\right)^{2}-2 N^{2} p(1-p) r(1-r)\left(\pi_{2}-\pi_{1}\right)^{2} \\
& =N p r(1-r) \pi_{1}\left(\left(1-2 \pi_{2}\right)-\left(1-2 \pi_{1}\right)\right) \\
& +2 N^{2} p r(1-r) \pi_{2}\left(\pi_{2}-\pi_{1}\right)-2 N^{2} p^{2} r(1-r)\left(\pi_{2}-\pi_{1}\right)^{2} \\
& -2 N^{2} p(1-p) r(1-r)\left(\pi_{2}-\pi_{1}\right)^{2}-2(N-1) r(1-r)\left(\pi_{2}-\pi_{1}\right) \mu_{I X} \\
& +N p\left(1-r^{2}\right) \pi_{1}\left(1-\pi_{1}\right)+N(1-p)\left(1-r^{2}\right) \pi_{2}\left(1-\pi_{2}\right) \\
& +N^{2} p(1-p)\left(1-r^{2}\right)\left(\pi_{2}-\pi_{1}\right)^{2} \\
& =-2 N p r(1-r) \pi_{1}\left(\pi_{2}-\pi_{1}\right)+2 N^{2} p r(1-r) \pi_{2}\left(\pi_{2}-\pi_{1}\right) \\
& -2 N^{2} p r(1-r)\left(\pi_{2}-\pi_{1}\right)^{2}-2(N-1) r(1-r)\left(\pi_{2}-\pi_{1}\right) \mu_{I X} \\
& +N p\left(1-r^{2}\right) \pi_{1}\left(1-\pi_{1}\right)+N(1-p)\left(1-r^{2}\right) \pi_{2}\left(1-\pi_{2}\right) \\
& +N^{2} p(1-p)\left(1-r^{2}\right)\left(\pi_{2}-\pi_{1}\right)^{2} \\
& =2(N-1) r(1-r)\left(\pi_{2}-\pi_{1}\right) N p \pi_{1}-2(N-1) r(1-r)\left(\pi_{2}-\pi_{1}\right) \mu_{I X} \\
& +N p\left(1-r^{2}\right) \pi_{1}\left(1-\pi_{1}\right)+N(1-p)\left(1-r^{2}\right) \pi_{2}\left(1-\pi_{2}\right) \\
& +N^{2} p(1-p)\left(1-r^{2}\right)\left(\pi_{2}-\pi_{1}\right)^{2} \text {. }
\end{aligned}
$$

This completes the proof.

\section{Binomial index of dispersion}

First, we consider the denominator of the BID (15) for the case of the LSET model $\left(r_{1}=r_{2}=r\right)$. Using (10), we obtain 


$$
\begin{aligned}
\frac{\mu_{X}}{N}\left(1-\frac{\mu_{X}}{N}\right)= & \left(p \pi_{1}+(1-p) \pi_{2}\right)\left(1-\left(p \pi_{1}+(1-p) \pi_{2}\right)\right) \\
= & p \pi_{1}+(1-p) \pi_{2}-p^{2} \pi_{1}^{2}-2 p(1-p) \pi_{1} \pi_{2}-(1-p)^{2} \pi_{2}^{2} \\
= & p \pi_{1}+(1-p) \pi_{2}-p \pi_{1}^{2} \\
& \quad+p(1-p) \pi_{1}^{2}-(1-p) \pi_{2}^{2}+p(1-p) \pi_{2}^{2}-2 p(1-p) \pi_{1} \pi_{2} \\
= & p \pi_{1}\left(1-\pi_{1}\right)+(1-p) \pi_{2}\left(1-\pi_{2}\right)+p(1-p)\left(\pi_{2}-\pi_{1}\right)^{2} .
\end{aligned}
$$

Then we look for matching terms in the numerator. First note that

$N^{2} p(1-p)\left(\pi_{2}-\pi_{1}\right)^{2}=N p(1-p)\left(\pi_{2}-\pi_{1}\right)^{2}+N(N-1) p(1-p)\left(\pi_{2}-\pi_{1}\right)^{2}$.

Using this together with (11) and (32), we find

$$
\begin{aligned}
\sigma_{X}^{2}= & \mu_{X}\left(1-\mu_{X} / N\right)+N(N-1) p(1-p)\left(\pi_{2}-\pi_{1}\right)^{2} \\
& +\frac{2 r}{1+r}(N-1)\left(\pi_{2}-\pi_{1}\right)\left(N p \pi_{1}-\mu_{I X}\right) .
\end{aligned}
$$

Bringing the results together leads to (16) for the BID. Note that only the last term, $\frac{2 r}{1+r} \ldots$, might become negative.

If $r=0,(16)$ reduces to

$$
\mathrm{BID}=1+\frac{p(1-p) N(N-1)\left(\pi_{2}-\pi_{1}\right)^{2}}{p \pi_{1}\left(1-\pi_{1}\right)+(1-p) \pi_{2}\left(1-\pi_{2}\right)+p(1-p)\left(\pi_{2}-\pi_{1}\right)^{2}} \geq 1 .
$$

\section{Autocovariance function}

By the law of total covariance, we obtain

$$
\begin{aligned}
\gamma(k) & :=\operatorname{Cov}\left[X_{t}, X_{t-k}\right]=\operatorname{Cov}\left[E\left[X_{t} \mid X_{t-1}, \ldots\right], E\left[X_{t-k} \mid X_{t-1}, \ldots\right]\right]+0 \\
& \stackrel{(8)}{=} \operatorname{Cov}\left[r X_{t-1}+N(1-r)\left(\pi_{2}+I_{t-1}\left(\pi_{1}-\pi_{2}\right)\right), X_{t-k}\right] \\
& =r \cdot \operatorname{Cov}\left[X_{t-1}, X_{t-k}\right]+N(1-r) \cdot\left(\pi_{1}-\pi_{2}\right) \cdot \operatorname{Cov}\left[I_{t-1}, X_{t-k}\right] \\
& =\cdots=r^{k} V\left[X_{t-k}\right]+N(1-r) \cdot\left(\pi_{1}-\pi_{2}\right) \cdot \sum_{s=1}^{k} r^{s-1} \operatorname{Cov}\left[I_{t-s}, X_{t-k}\right],
\end{aligned}
$$

which proves (18).

\section{Appendix 2: Tables}

See Tables 5, 6, 7 and 8 . 
Table 5 Conditional least squares and conditional maximum likelihood estimates for $\left(r, \pi_{1}, \pi_{2}\right)$ and $R$ in the LSET-BAR(1) model. Model M1: $\left(N, R ; r, \pi_{1}, \pi_{2}\right)=(40,10 ; 0.3,0.15,0.4)$

\begin{tabular}{|c|c|c|c|c|c|c|c|c|c|}
\hline \multirow[t]{2}{*}{$T$} & \multirow[t]{2}{*}{$R$} & \multicolumn{4}{|l|}{ CLS } & \multicolumn{4}{|l|}{ CML } \\
\hline & & $r$ & $\pi_{1}$ & $\pi_{2}$ & Percent & $r$ & $\pi_{1}$ & $\pi_{2}$ & Percent \\
\hline \multirow[t]{5}{*}{100} & 8 & $\begin{array}{l}0.57 \\
(0.18)\end{array}$ & $\begin{array}{l}0.17 \\
(0.16)\end{array}$ & $\begin{array}{l}0.31 \\
(0.27)\end{array}$ & 3.2 & $\begin{array}{l}0.39 \\
(0.11)\end{array}$ & $\begin{array}{l}0.15 \\
(0.03)\end{array}$ & $\begin{array}{l}0.32 \\
(0.09)\end{array}$ & 4.1 \\
\hline & 9 & $\begin{array}{l}0.42 \\
(0.14)\end{array}$ & $\begin{array}{l}0.16 \\
(0.02)\end{array}$ & $\begin{array}{l}0.35 \\
(0.07)\end{array}$ & 8.5 & $\begin{array}{l}0.33 \\
(0.11)\end{array}$ & $\begin{array}{l}0.15 \\
(0.03)\end{array}$ & $\begin{array}{l}0.35 \\
(0.09)\end{array}$ & 7.3 \\
\hline & 10 & $\begin{array}{l}0.27 \\
(0.08)\end{array}$ & $\begin{array}{l}0.15 \\
(0.02)\end{array}$ & $\begin{array}{l}0.39 \\
(0.03)\end{array}$ & 83.7 & $\begin{array}{l}0.26 \\
(0.12)\end{array}$ & $\begin{array}{l}0.14 \\
(0.04)\end{array}$ & $\begin{array}{l}0.37 \\
(0.10)\end{array}$ & 84.9 \\
\hline & 11 & $\begin{array}{l}0.39 \\
(0.13)\end{array}$ & $\begin{array}{l}0.18 \\
(0.05)\end{array}$ & $\begin{array}{l}0.39 \\
(0.03)\end{array}$ & 2.9 & $\begin{array}{l}0.32 \\
(0.11)\end{array}$ & $\begin{array}{l}0.17 \\
(0.06)\end{array}$ & $\begin{array}{l}0.37 \\
(0.09)\end{array}$ & 3.1 \\
\hline & 12 & $\begin{array}{l}0.53 \\
(0.16)\end{array}$ & $\begin{array}{l}0.21 \\
(0.07)\end{array}$ & $\begin{array}{l}0.37 \\
(0.06)\end{array}$ & 1.7 & $\begin{array}{l}0.37 \\
(0.12)\end{array}$ & $\begin{array}{l}0.18 \\
(0.07)\end{array}$ & $\begin{array}{l}0.37 \\
(0.09)\end{array}$ & 0.6 \\
\hline \multirow[t]{5}{*}{500} & 8 & $\begin{array}{l}0.64 \\
(0.08)\end{array}$ & $\begin{array}{l}0.17 \\
(0.01)\end{array}$ & $\begin{array}{l}0.35 \\
(0.03)\end{array}$ & 0 & $\begin{array}{l}0.42 \\
(0.03)\end{array}$ & $\begin{array}{l}0.16 \\
(0.01)\end{array}$ & $\begin{array}{l}0.36 \\
(0.02)\end{array}$ & 0 \\
\hline & 9 & $\begin{array}{l}0.46 \\
(0.01)\end{array}$ & $\begin{array}{l}0.15 \\
(0.01)\end{array}$ & $\begin{array}{l}0.38 \\
(0.00)\end{array}$ & 0 & $\begin{array}{l}0.36 \\
(0.04)\end{array}$ & $\begin{array}{l}0.15 \\
(0.01)\end{array}$ & $\begin{array}{l}0.38 \\
(0.01)\end{array}$ & 0 \\
\hline & 10 & $\begin{array}{l}0.29 \\
(0.05)\end{array}$ & $\begin{array}{l}0.15 \\
(0.00)\end{array}$ & $\begin{array}{l}0.40 \\
(0.00)\end{array}$ & 99.9 & $\begin{array}{l}0.29 \\
(0.04)\end{array}$ & $\begin{array}{l}0.15 \\
(0.01)\end{array}$ & $\begin{array}{l}0.40 \\
(0.01)\end{array}$ & 100 \\
\hline & 11 & $\begin{array}{l}0.43 \\
(0.06)\end{array}$ & $\begin{array}{l}0.16 \\
(0.01)\end{array}$ & $\begin{array}{l}0.40 \\
(0.01)\end{array}$ & 0.1 & $\begin{array}{l}0.35 \\
(0.04)\end{array}$ & $\begin{array}{l}0.16 \\
(0.01)\end{array}$ & $\begin{array}{l}0.40 \\
(0.01)\end{array}$ & 0 \\
\hline & 12 & $\begin{array}{l}0.58 \\
(0.07)\end{array}$ & $\begin{array}{l}0.19 \\
(0.02)\end{array}$ & $\begin{array}{l}0.38 \\
(0.01)\end{array}$ & 0 & $\begin{array}{l}0.41 \\
(0.03)\end{array}$ & $\begin{array}{l}0.18 \\
(0.02)\end{array}$ & $\begin{array}{l}0.39 \\
(0.01)\end{array}$ & 0 \\
\hline \multirow[t]{5}{*}{1000} & 8 & $\begin{array}{l}0.64 \\
(0.06)\end{array}$ & $\begin{array}{l}0.17 \\
(0.01)\end{array}$ & $\begin{array}{l}0.35 \\
(0.02)\end{array}$ & 0 & $\begin{array}{l}0.43 \\
(0.02)\end{array}$ & $\begin{array}{l}0.15 \\
(0.00)\end{array}$ & $\begin{array}{l}0.36 \\
(0.01)\end{array}$ & 0 \\
\hline & 9 & $\begin{array}{l}0.46 \\
(0.05)\end{array}$ & $\begin{array}{l}0.15 \\
(0.00)\end{array}$ & $\begin{array}{l}0.38 \\
(0.01)\end{array}$ & 0 & $\begin{array}{l}0.36 \\
(0.02)\end{array}$ & $\begin{array}{l}0.15 \\
(0.00)\end{array}$ & $\begin{array}{l}0.38 \\
(0.00)\end{array}$ & 0 \\
\hline & 10 & $\begin{array}{l}0.30 \\
(0.03)\end{array}$ & $\begin{array}{l}0.15 \\
(0.00)\end{array}$ & $\begin{array}{l}0.40 \\
(0.00)\end{array}$ & 100 & $\begin{array}{l}0.30 \\
(0.03)\end{array}$ & $\begin{array}{l}0.15 \\
(0.00)\end{array}$ & $\begin{array}{l}0.40 \\
(0.00)\end{array}$ & 100 \\
\hline & 11 & $\begin{array}{l}0.44 \\
(0.04)\end{array}$ & $\begin{array}{l}0.16 \\
(0.01)\end{array}$ & $\begin{array}{l}0.40 \\
(0.01)\end{array}$ & 0 & $\begin{array}{l}0.36 \\
(0.02)\end{array}$ & $\begin{array}{l}0.16 \\
(0.01)\end{array}$ & $\begin{array}{l}0.40 \\
(0.01)\end{array}$ & 0 \\
\hline & 12 & $\begin{array}{l}0.59 \\
(0.05)\end{array}$ & $\begin{array}{l}0.18 \\
(0.01)\end{array}$ & $\begin{array}{l}0.39 \\
(0.01)\end{array}$ & 0 & $\begin{array}{l}0.41 \\
(0.02)\end{array}$ & $\begin{array}{l}0.17 \\
(0.01)\end{array}$ & $\begin{array}{l}0.40 \\
(0.01)\end{array}$ & 0 \\
\hline
\end{tabular}

Standard errors in parentheses 
Table 6 Conditional least squares and conditional maximum likelihood estimates for $\left(r, \pi_{1}, \pi_{2}\right)$ and $R$ in the LSET-BAR(1) model. Model M2: $\left(N, R ; r, \pi_{1}, \pi_{2}\right)=(20,4 ; 0.3,0.15,0.4)$

\begin{tabular}{|c|c|c|c|c|c|c|c|c|c|}
\hline \multirow[t]{2}{*}{$T$} & \multirow[t]{2}{*}{$R$} & \multicolumn{4}{|l|}{ CLS } & \multicolumn{4}{|l|}{ CML } \\
\hline & & $r$ & $\pi_{1}$ & $\pi_{2}$ & Percent & $r$ & $\pi_{1}$ & $\pi_{2}$ & Percent \\
\hline \multirow[t]{5}{*}{100} & 2 & $\begin{array}{l}0.61 \\
(0.13)\end{array}$ & $\begin{array}{l}0.25 \\
(0.10)\end{array}$ & $\begin{array}{l}0.34 \\
(0.05)\end{array}$ & 4.9 & $\begin{array}{l}0.48 \\
(0.08)\end{array}$ & $\begin{array}{l}0.20 \\
(0.06)\end{array}$ & $\begin{array}{l}0.35 \\
(0.04)\end{array}$ & 5.1 \\
\hline & 3 & $\begin{array}{l}0.49 \\
(0.13)\end{array}$ & $\begin{array}{l}0.19 \\
(0.05)\end{array}$ & $\begin{array}{l}0.37 \\
(0.03)\end{array}$ & 1.5 & $\begin{array}{l}0.40 \\
(0.09)\end{array}$ & $\begin{array}{l}0.17 \\
(0.05)\end{array}$ & $\begin{array}{l}0.37 \\
(0.03)\end{array}$ & 1.7 \\
\hline & 4 & $\begin{array}{l}0.27 \\
(0.11)\end{array}$ & $\begin{array}{l}0.16 \\
(0.03)\end{array}$ & $\begin{array}{l}0.40 \\
(0.02)\end{array}$ & 91.9 & $\begin{array}{l}0.28 \\
(0.11)\end{array}$ & $\begin{array}{l}0.16 \\
(0.04)\end{array}$ & $\begin{array}{l}0.39 \\
(0.04)\end{array}$ & 92.0 \\
\hline & 5 & $\begin{array}{l}0.42 \\
(0.14)\end{array}$ & $\begin{array}{l}0.25 \\
(0.06)\end{array}$ & $\begin{array}{l}0.39 \\
(0.03)\end{array}$ & 1.7 & $\begin{array}{l}0.36 \\
(0.09)\end{array}$ & $\begin{array}{l}0.23 \\
(0.06)\end{array}$ & $\begin{array}{l}0.39 \\
(0.02)\end{array}$ & 1.1 \\
\hline & 6 & $\begin{array}{l}0.62 \\
(0.17)\end{array}$ & $\begin{array}{l}0.37 \\
(0.41)\end{array}$ & $\begin{array}{l}0.30 \\
(0.52)\end{array}$ & 0 & $\begin{array}{l}0.43 \\
(0.08)\end{array}$ & $\begin{array}{l}0.28 \\
(0.07)\end{array}$ & $\begin{array}{l}0.38 \\
(0.02)\end{array}$ & 0.1 \\
\hline \multirow[t]{5}{*}{500} & 2 & $\begin{array}{l}0.63 \\
(0.06)\end{array}$ & $\begin{array}{l}0.22 \\
(0.03)\end{array}$ & $\begin{array}{l}0.35 \\
(0.02)\end{array}$ & 0 & $\begin{array}{l}0.48 \\
(0.03)\end{array}$ & $\begin{array}{l}0.18 \\
(0.02)\end{array}$ & $\begin{array}{l}0.36 \\
(0.02)\end{array}$ & 0 \\
\hline & 3 & $\begin{array}{l}0.50 \\
(0.06)\end{array}$ & $\begin{array}{l}0.17 \\
(0.02)\end{array}$ & $\begin{array}{l}0.37 \\
(0.01)\end{array}$ & 0 & $\begin{array}{l}0.41 \\
(0.04)\end{array}$ & $\begin{array}{l}0.16 \\
(0.01)\end{array}$ & $\begin{array}{l}0.38 \\
(0.01)\end{array}$ & 0 \\
\hline & 4 & $\begin{array}{l}0.29 \\
(0.05)\end{array}$ & $\begin{array}{l}0.15 \\
(0.01)\end{array}$ & $\begin{array}{l}0.40 \\
(0.01)\end{array}$ & 100 & $\begin{array}{l}0.30 \\
(0.05)\end{array}$ & $\begin{array}{l}0.15 \\
(0.01)\end{array}$ & $\begin{array}{l}0.40 \\
(0.01)\end{array}$ & 100 \\
\hline & 5 & $\begin{array}{l}0.46 \\
(0.06)\end{array}$ & $\begin{array}{l}0.23 \\
(0.02)\end{array}$ & $\begin{array}{l}0.39 \\
(0.01)\end{array}$ & 0 & $\begin{array}{l}0.38 \\
(0.04)\end{array}$ & $\begin{array}{l}0.22 \\
(0.02)\end{array}$ & $\begin{array}{l}0.40 \\
(0.01)\end{array}$ & 0 \\
\hline & 6 & $\begin{array}{l}0.67 \\
(0.07)\end{array}$ & $\begin{array}{l}0.33 \\
(0.04)\end{array}$ & $\begin{array}{l}0.34 \\
(0.04)\end{array}$ & 0 & $\begin{array}{l}0.45 \\
(0.03)\end{array}$ & $\begin{array}{l}0.27 \\
(0.03)\end{array}$ & $\begin{array}{l}0.39 \\
(0.01)\end{array}$ & 0 \\
\hline \multirow[t]{5}{*}{1000} & 2 & $\begin{array}{l}0.63 \\
(0.04)\end{array}$ & $\begin{array}{l}0.22 \\
(0.02)\end{array}$ & $\begin{array}{l}0.35 \\
(0.01)\end{array}$ & 0 & $\begin{array}{l}0.48 \\
(0.02)\end{array}$ & $\begin{array}{l}0.18 \\
(0.01)\end{array}$ & $\begin{array}{l}0.36 \\
(0.01)\end{array}$ & 0 \\
\hline & 3 & $\begin{array}{l}0.51 \\
(0.04)\end{array}$ & $\begin{array}{l}0.17 \\
(0.01)\end{array}$ & $\begin{array}{l}0.37 \\
(0.01)\end{array}$ & 0 & $\begin{array}{l}0.41 \\
(0.02)\end{array}$ & $\begin{array}{l}0.16 \\
(0.01)\end{array}$ & $\begin{array}{l}0.38 \\
(0.01)\end{array}$ & 0 \\
\hline & 4 & $\begin{array}{l}0.30 \\
(0.03)\end{array}$ & $\begin{array}{l}0.15 \\
(0.01)\end{array}$ & $\begin{array}{l}0.40 \\
(0.01)\end{array}$ & 100 & $\begin{array}{l}0.30 \\
(0.03)\end{array}$ & $\begin{array}{l}0.15 \\
(0.01)\end{array}$ & $\begin{array}{l}0.40 \\
(0.01)\end{array}$ & 100 \\
\hline & 5 & $\begin{array}{l}0.46 \\
(0.04)\end{array}$ & $\begin{array}{l}0.23 \\
(0.02)\end{array}$ & $\begin{array}{l}0.39 \\
(0.01)\end{array}$ & 0 & $\begin{array}{l}0.38 \\
(0.03)\end{array}$ & $\begin{array}{l}0.22 \\
(0.02)\end{array}$ & $\begin{array}{l}0.40 \\
(0.01)\end{array}$ & 0 \\
\hline & 6 & $\begin{array}{l}0.68 \\
(0.05)\end{array}$ & $\begin{array}{l}0.33 \\
(0.03)\end{array}$ & $\begin{array}{l}0.34 \\
(0.02)\end{array}$ & 0 & $\begin{array}{l}0.46 \\
(0.02)\end{array}$ & $\begin{array}{l}0.27 \\
(0.02)\end{array}$ & $\begin{array}{l}0.39 \\
(0.01)\end{array}$ & 0 \\
\hline
\end{tabular}

Standard errors in parentheses 
Table 7 Conditional least squares and conditional maximum likelihood estimates for $\left(r, \pi_{1}, \pi_{2}\right)$ and $R$ in the LSET-BAR(1) model. Model M3: $\left(N, R ; r, \pi_{1}, \pi_{2}\right)=(40,10 ; 0.7,0.15,0.4)$

\begin{tabular}{|c|c|c|c|c|c|c|c|c|c|}
\hline \multirow[t]{2}{*}{$T$} & \multirow[t]{2}{*}{$R$} & \multicolumn{4}{|l|}{ CLS } & \multicolumn{4}{|l|}{ CML } \\
\hline & & $r$ & $\pi_{1}$ & $\pi_{2}$ & Percent & $r$ & $\pi_{1}$ & $\pi_{2}$ & Percent \\
\hline \multirow[t]{5}{*}{100} & 8 & $\begin{array}{l}0.77 \\
(0.11)\end{array}$ & $\begin{array}{l}0.18 \\
(0.07)\end{array}$ & $\begin{array}{l}0.28 \\
(0.13)\end{array}$ & 2.8 & $\begin{array}{l}0.71 \\
(0.04)\end{array}$ & $\begin{array}{l}0.16 \\
(0.06)\end{array}$ & $\begin{array}{l}0.30 \\
(0.11)\end{array}$ & 3.6 \\
\hline & 9 & $\begin{array}{l}0.71 \\
(0.09)\end{array}$ & $\begin{array}{l}0.17 \\
(0.05)\end{array}$ & $\begin{array}{l}0.32 \\
(0.11)\end{array}$ & 12 & $\begin{array}{l}0.70 \\
(0.04)\end{array}$ & $\begin{array}{l}0.16 \\
(0.05)\end{array}$ & $\begin{array}{l}0.32 \\
(0.12)\end{array}$ & 12.2 \\
\hline & 10 & $\begin{array}{l}0.66 \\
(0.08)\end{array}$ & $\begin{array}{l}0.17 \\
(0.05)\end{array}$ & $\begin{array}{l}0.37 \\
(0.07)\end{array}$ & 61.5 & $\begin{array}{l}0.69 \\
(0.05)\end{array}$ & $\begin{array}{l}0.17 \\
(0.05)\end{array}$ & $\begin{array}{l}0.37 \\
(0.08)\end{array}$ & 61.5 \\
\hline & 11 & $\begin{array}{l}0.71 \\
(0.09)\end{array}$ & $\begin{array}{l}0.21 \\
(0.10)\end{array}$ & $\begin{array}{l}0.38 \\
(0.06)\end{array}$ & 8.9 & $\begin{array}{l}0.70 \\
(0.04)\end{array}$ & $\begin{array}{l}0.21 \\
(0.11)\end{array}$ & $\begin{array}{l}0.38 \\
(0.07)\end{array}$ & 8.9 \\
\hline & 12 & $\begin{array}{l}0.76 \\
(0.10)\end{array}$ & $\begin{array}{l}0.21 \\
(0.10)\end{array}$ & $\begin{array}{l}0.37 \\
(0.08)\end{array}$ & 3.8 & $\begin{array}{l}0.71 \\
(0.04)\end{array}$ & $\begin{array}{l}0.22 \\
(0.10)\end{array}$ & $\begin{array}{l}0.38 \\
(0.07)\end{array}$ & 3.8 \\
\hline \multirow[t]{5}{*}{500} & 8 & $\begin{array}{l}0.83 \\
(0.05)\end{array}$ & $\begin{array}{l}0.17 \\
(0.02)\end{array}$ & $\begin{array}{l}0.34 \\
(0.05)\end{array}$ & 0 & $\begin{array}{l}0.72 \\
(0.02)\end{array}$ & $\begin{array}{l}0.15 \\
(0.01)\end{array}$ & $\begin{array}{l}0.36 \\
(0.03)\end{array}$ & 0 \\
\hline & 9 & $\begin{array}{l}0.76 \\
(0.04)\end{array}$ & $\begin{array}{l}0.15 \\
(0.01)\end{array}$ & $\begin{array}{l}0.37 \\
(0.03)\end{array}$ & 0.5 & $\begin{array}{l}0.70 \\
(0.02)\end{array}$ & $\begin{array}{l}0.15 \\
(0.01)\end{array}$ & $\begin{array}{l}0.38 \\
(0.02)\end{array}$ & 1 \\
\hline & 10 & $\begin{array}{l}0.69 \\
(0.04)\end{array}$ & $\begin{array}{l}0.15 \\
(0.01)\end{array}$ & $\begin{array}{l}0.40 \\
(0.02)\end{array}$ & 97.4 & $\begin{array}{l}0.70 \\
(0.02)\end{array}$ & $\begin{array}{l}0.15 \\
(0.01)\end{array}$ & $\begin{array}{l}0.40 \\
(0.02)\end{array}$ & 97.2 \\
\hline & 11 & $\begin{array}{l}0.74 \\
(0.04)\end{array}$ & $\begin{array}{l}0.16 \\
(0.02)\end{array}$ & $\begin{array}{l}0.39 \\
(0.02)\end{array}$ & 1.9 & $\begin{array}{l}0.70 \\
(0.02)\end{array}$ & $\begin{array}{l}0.16 \\
(0.02)\end{array}$ & $\begin{array}{l}0.40 \\
(0.02)\end{array}$ & 1.6 \\
\hline & 12 & $\begin{array}{l}0.80 \\
(0.05)\end{array}$ & $\begin{array}{l}0.19 \\
(0.03)\end{array}$ & $\begin{array}{l}0.38 \\
(0.02)\end{array}$ & 0.2 & $\begin{array}{l}0.71 \\
(0.02)\end{array}$ & $\begin{array}{l}0.17 \\
(0.02)\end{array}$ & $\begin{array}{l}0.40 \\
(0.02)\end{array}$ & 0.2 \\
\hline \multirow[t]{5}{*}{1000} & 8 & $\begin{array}{l}0.84 \\
(0.03)\end{array}$ & $\begin{array}{l}0.16 \\
(0.03)\end{array}$ & $\begin{array}{l}0.34 \\
(0.03)\end{array}$ & 0 & $\begin{array}{l}0.72 \\
(0.01)\end{array}$ & $\begin{array}{l}0.15 \\
(0.01)\end{array}$ & $\begin{array}{l}0.36 \\
(0.02)\end{array}$ & 0 \\
\hline & 9 & $\begin{array}{l}0.76 \\
(0.03)\end{array}$ & $\begin{array}{l}0.15 \\
(0.01)\end{array}$ & $\begin{array}{l}0.38 \\
(0.02)\end{array}$ & 0 & $\begin{array}{l}0.71 \\
(0.01)\end{array}$ & $\begin{array}{l}0.15 \\
(0.01)\end{array}$ & $\begin{array}{l}0.38 \\
(0.01)\end{array}$ & 0 \\
\hline & 10 & $\begin{array}{l}0.70 \\
(0.02)\end{array}$ & $\begin{array}{l}0.15 \\
(0.01)\end{array}$ & $\begin{array}{l}0.40 \\
(0.01)\end{array}$ & 99.9 & $\begin{array}{l}0.70 \\
(0.01)\end{array}$ & $\begin{array}{l}0.15 \\
(0.00)\end{array}$ & $\begin{array}{l}0.40 \\
(0.02)\end{array}$ & 99.9 \\
\hline & 11 & $\begin{array}{l}0.75 \\
(0.03)\end{array}$ & $\begin{array}{l}0.16 \\
(0.01)\end{array}$ & $\begin{array}{l}0.39 \\
(0.01)\end{array}$ & 0.1 & $\begin{array}{l}0.71 \\
(0.01)\end{array}$ & $\begin{array}{l}0.16 \\
(0.01)\end{array}$ & $\begin{array}{l}0.39 \\
(0.01)\end{array}$ & 0.1 \\
\hline & 12 & $\begin{array}{l}0.81 \\
(0.03)\end{array}$ & $\begin{array}{l}0.18 \\
(0.02)\end{array}$ & $\begin{array}{l}0.38 \\
(0.02)\end{array}$ & 0 & $\begin{array}{l}0.71 \\
(0.01)\end{array}$ & $\begin{array}{l}0.17 \\
(0.01)\end{array}$ & $\begin{array}{l}0.40 \\
(0.01)\end{array}$ & 0 \\
\hline
\end{tabular}

Standard errors in parentheses 
Table 8 Conditional least squares and conditional maximum likelihood estimates for $\left(r, \pi_{1}, \pi_{2}\right)$ and $R$ in the LSET-BAR(1) model. Model M4: $\left(N, R ; r, \pi_{1}, \pi_{2}\right)=(20,5 ; 0.7,0.15,0.4)$

\begin{tabular}{|c|c|c|c|c|c|c|c|c|c|}
\hline \multirow[t]{2}{*}{$T$} & \multirow[t]{2}{*}{$R$} & \multicolumn{4}{|l|}{ CLS } & \multicolumn{4}{|l|}{ CML } \\
\hline & & $r$ & $\pi_{1}$ & $\pi_{2}$ & Percent & $r$ & $\pi_{1}$ & $\pi_{2}$ & Percent \\
\hline \multirow[t]{5}{*}{100} & 3 & $\begin{array}{l}0.82 \\
(0.10)\end{array}$ & $\begin{array}{l}0.23 \\
(0.14)\end{array}$ & $\begin{array}{l}0.24 \\
(0.10)\end{array}$ & 6.5 & $\begin{array}{l}0.73 \\
(0.04)\end{array}$ & $\begin{array}{l}0.17 \\
(0.05)\end{array}$ & $\begin{array}{l}0.27 \\
(0.09)\end{array}$ & 3.1 \\
\hline & 4 & $\begin{array}{l}0.75 \\
(0.10)\end{array}$ & $\begin{array}{l}0.17 \\
(0.05)\end{array}$ & $\begin{array}{l}0.29 \\
(0.10)\end{array}$ & 1.1 & $\begin{array}{l}0.71 \\
(0.05)\end{array}$ & $\begin{array}{l}0.16 \\
(0.03)\end{array}$ & $\begin{array}{l}0.31 \\
(0.10)\end{array}$ & 7.8 \\
\hline & 5 & $\begin{array}{l}0.65 \\
(0.09)\end{array}$ & $\begin{array}{l}0.16 \\
(0.03)\end{array}$ & $\begin{array}{l}0.37 \\
(0.07)\end{array}$ & 68.9 & $\begin{array}{l}0.69 \\
(0.04)\end{array}$ & $\begin{array}{l}0.16 \\
(0.05)\end{array}$ & $\begin{array}{l}0.37 \\
(0.09)\end{array}$ & 74.8 \\
\hline & 6 & $\begin{array}{l}0.76 \\
(0.09)\end{array}$ & $\begin{array}{l}0.21 \\
(0.08)\end{array}$ & $\begin{array}{l}0.34 \\
(0.10)\end{array}$ & 9.9 & $\begin{array}{l}0.71 \\
(0.04)\end{array}$ & $\begin{array}{l}0.19 \\
(0.05)\end{array}$ & $\begin{array}{l}0.36 \\
(0.09)\end{array}$ & 9.8 \\
\hline & 7 & $\begin{array}{l}0.82 \\
(0.08)\end{array}$ & $\begin{array}{l}0.24 \\
(0.10)\end{array}$ & $\begin{array}{l}0.29 \\
(0.12)\end{array}$ & 3.9 & $\begin{array}{l}0.73 \\
(0.04)\end{array}$ & $\begin{array}{l}0.21 \\
(0.06)\end{array}$ & $\begin{array}{l}0.35 \\
(0.10)\end{array}$ & 4.5 \\
\hline \multirow[t]{5}{*}{500} & 3 & $\begin{array}{l}0.90 \\
(0.03)\end{array}$ & $\begin{array}{l}0.28 \\
(0.14)\end{array}$ & $\begin{array}{l}0.19 \\
(0.16)\end{array}$ & 0 & $\begin{array}{l}0.73 \\
(0.02)\end{array}$ & $\begin{array}{l}0.16 \\
(0.01)\end{array}$ & $\begin{array}{l}0.29 \\
(0.04)\end{array}$ & 0 \\
\hline & 4 & $\begin{array}{l}0.81 \\
(0.04)\end{array}$ & $\begin{array}{l}0.17 \\
(0.02)\end{array}$ & $\begin{array}{l}0.32 \\
(0.05)\end{array}$ & 0 & $\begin{array}{l}0.71 \\
(0.02)\end{array}$ & $\begin{array}{l}0.15 \\
(0.01)\end{array}$ & $\begin{array}{l}0.04 \\
(0.03)\end{array}$ & 0 \\
\hline & 5 & $\begin{array}{l}0.69 \\
(0.04)\end{array}$ & $\begin{array}{l}0.15 \\
(0.01)\end{array}$ & $\begin{array}{l}0.40 \\
(0.02)\end{array}$ & 99.5 & $\begin{array}{l}0.70 \\
(0.02)\end{array}$ & $\begin{array}{l}0.15 \\
(0.01)\end{array}$ & $\begin{array}{l}0.40 \\
(0.02)\end{array}$ & 99.9 \\
\hline & 6 & $\begin{array}{l}0.80 \\
(0.04)\end{array}$ & $\begin{array}{l}0.19 \\
(0.03)\end{array}$ & $\begin{array}{l}0.37 \\
(0.04)\end{array}$ & 0.4 & $\begin{array}{l}0.71 \\
(0.02)\end{array}$ & $\begin{array}{l}0.17 \\
(0.02)\end{array}$ & $\begin{array}{l}0.39 \\
(0.02)\end{array}$ & 0.1 \\
\hline & 7 & $\begin{array}{l}0.88 \\
(0.04)\end{array}$ & $\begin{array}{l}0.24 \\
(0.13)\end{array}$ & $\begin{array}{l}0.26 \\
(0.34)\end{array}$ & 0.1 & $\begin{array}{l}0.73 \\
(0.02)\end{array}$ & $\begin{array}{l}0.19 \\
(0.02)\end{array}$ & $\begin{array}{l}0.39 \\
(0.03)\end{array}$ & 0 \\
\hline \multirow[t]{5}{*}{1000} & 3 & $\begin{array}{l}0.90 \\
(0.02)\end{array}$ & $\begin{array}{l}0.27 \\
(0.05)\end{array}$ & $\begin{array}{l}0.20 \\
(0.08)\end{array}$ & 0 & $\begin{array}{l}0.74 \\
(0.01)\end{array}$ & $\begin{array}{l}0.16 \\
(0.01)\end{array}$ & $\begin{array}{l}0.30 \\
(0.03)\end{array}$ & 0 \\
\hline & 4 & $\begin{array}{l}0.82 \\
(0.03)\end{array}$ & $\begin{array}{l}0.17 \\
(0.01)\end{array}$ & $\begin{array}{l}0.32 \\
(0.03)\end{array}$ & 0 & $\begin{array}{l}0.71 \\
(0.01)\end{array}$ & $\begin{array}{l}0.15 \\
(0.01)\end{array}$ & $\begin{array}{l}0.3 \\
(0.02)\end{array}$ & 0 \\
\hline & 5 & $\begin{array}{l}0.69 \\
(0.02)\end{array}$ & $\begin{array}{l}0.15 \\
(0.01)\end{array}$ & $\begin{array}{l}0.40 \\
(0.01)\end{array}$ & 99.9 & $\begin{array}{l}0.70 \\
(0.01)\end{array}$ & $\begin{array}{l}0.15 \\
(0.01)\end{array}$ & $\begin{array}{l}0.40 \\
(0.01)\end{array}$ & 99.9 \\
\hline & 6 & $\begin{array}{l}0.80 \\
(0.03)\end{array}$ & $\begin{array}{l}0.18 \\
(0.02)\end{array}$ & $\begin{array}{l}0.37 \\
(0.02)\end{array}$ & 0.1 & $\begin{array}{l}0.71 \\
(0.01)\end{array}$ & $\begin{array}{l}0.17 \\
(0.01)\end{array}$ & $\begin{array}{l}0.40 \\
(0.01)\end{array}$ & 0.1 \\
\hline & 7 & $\begin{array}{l}0.88 \\
(0.03)\end{array}$ & $\begin{array}{l}0.23 \\
(0.04)\end{array}$ & $\begin{array}{l}0.26 \\
(0.08)\end{array}$ & 0 & $\begin{array}{l}0.73 \\
(0.01)\end{array}$ & $\begin{array}{l}0.19 \\
(0.02)\end{array}$ & $\begin{array}{l}0.39 \\
(0.02)\end{array}$ & 0 \\
\hline
\end{tabular}

Standard errors in parentheses 


\section{References}

Billingsley, P.: Statistical Inference for Markov Processes. Statistical Research Monographs. University of Chicago Press, Chicago (1961)

Chan, K.S., Tong, H.: On the use of the deterministic Lyapunov function for the ergodicity of stochastic difference equations. Adv. Appl. Probab. 17, 666-678 (1985)

Chan, K.S., Petruccelli, J.D., Tong, H., Woolford, S.W.: A multiple-threshold AR(1) model. J. Appl. Probab. 22, 267-279 (1985)

Chan, W.S., Wong, A.C.S., Tong, H.: Some nonlinear threshold autoregressive time series models for actuarial use. N. Am. Actuar. J. 8, 37-61 (2004). doi:10.1080/10920277.2004.10596170

Chan, K.S., Li, D., Ling, S., Tong, H.: On conditionally heteroscedastic AR models with thresholds. Stat. Sin. 24(2), 625-652 (2014)

Chen, C.W.S., So, M.K.P., Liu, F.C.: A review of threshold time series models in finance. Stat. Interface 4, 167-182 (2011)

Cline, D.B.H., Pu, H.H.: Stability of nonlinear AR(1) time series with delay. Stoch. Processes Appl. 82, 307-333 (1999)

Cline, D.B.H., Pu, H.H.: Stability and the Lyapounov exponent of threshold AR-ARCH models. Ann. Appl. Probab. 14, 1920-1949 (2004)

Corradi, V., Swanson, N.R.: Predictive density and conditional confidence interval accuracy tests. J. Econom. 135(1-2), 187-228 (2006)

Hansen, B.E.: Threshold autoregression in economics. Stat. Interface 4, 123-127 (2011)

Klimko, L.A., Nelson, P.I.: On conditional least squares estimation for stochastic processes. Ann. Stat. 6, 629-642 (1978)

Lanne, M., Saikkonen, P.: Non-linear GARCH models for highly persistent volatility. Econom. J. 8, 251-276 (2005)

Liebscher, E.: Towards a unified approach for proving geometric ergodicity and mixing properties of nonlinear autoregressive processes. J. Time Ser. Anal. 26, 669-689 (2005)

McKenzie, E.: Some simple models for discrete variate time series. Water Resour. Bull. 21, 645-650 (1985). doi:10.1111/j.1752-1688.1985.tb05379.x

Möller, T., Weiß, C.H.: Threshold models for integer-valued time series with infinite or finite range. In: Steland, A., Rafajłowicz, E., Szajowski, K. (eds.) Stochastic Models, Statistics and Their Applications, Springer Proceedings in Mathematics \& Statistics, vol. 122, Springer, Berlin, pp. 327-334 (2015). doi:10.1007/978-3-319-13881-7_36

Monteiro, M., Scotto, M.G., Pereira, I.: Integer-valued self-exciting threshold autoregressive processes. Commun. Stat. Theory Methods 41, 2717-2737 (2012)

Petruccelli, J.D.: A comparison of tests for setar-type non-linearity in time series. J. Forecast. 9(1), 25-36 (1990). doi:10.1002/for.3980090104

Robert-Koch-Institut: Robert-Koch-Institut: SurvStat@RKI. http://www3.rki.de/SurvStat. Accessed 201407-02 (2014)

Samia, N.I., Chan, K.S., Stenseth, N.C.: A generalized threshold mixed model for analyzing nonnormal nonlinear time series, with application to plague in Kazakhstan. Biometrika 94(1), 101-118 (2007). doi:10.1093/biomet/asm006

Scotto, M., Weiß, C.H., Silva, M.E., Pereira, I.: Bivariate binomial autoregressive models. J. Multivar. Anal. 125, 233-251 (2014)

Stenseth, N.C., Samia, N.I., Viljugrein, H., Kausrud, K.L., Begon, M., Davis, S., Leirs, H., Dubyanskiy, V.M., Esper, J., Ageyev, V.S., Klassovskiy, N.L., Pole, S.B., Chan, K.S.: Plague dynamics are driven by climate variation. In: Proceedings of the National Academy of Sciences, vol. 103, pp. 13110-13115 (2006). doi:10.1073/pnas.0602447103, http://www.pnas.org/content/103/35/13110.full.pdf+html

Steutel, F.W., van Harn, K.: Discrete analogues of self-decomposability and stability. Ann. Probab. 7, 893-899 (1979)

Thyregod, P., Carstensen, J., Madsen, H., Arnbjerg-Nielsen, K.: Integer valued autoregressive models for tipping bucket rainfall measurements. Environmetrics 10(4), 395-411 (1999). doi:10.1002/ (SICI)1099-095X(199907/08)10:4<395:AID-ENV364>3.0.CO;2-M

Tong, H.: Threshold models in non-linear time series analysis. Lecture Notes in Statistics, vol. 21. Springer (1983)

Tong, H.: Non-linear Time Series. A Dynamical System Approach. Clarendon Press, Oxford (1990)

Tong, H.: Threshold models in time series analysis-30 years on. Stat. Interface 4, 107-118 (2011) 
Tong, H., Lim, K.S.: Threshold autoregression, limit cycles and cyclical data. J. R. Stat. Soci. Ser. B 42, 245-292 (1980)

Turkman, K.F., Scotto, M.G., de Zea, Bermudez P.: Non-linear Time Series: Extreme Events and Integer Value Problems. Springer, Basel (2014)

Wang, C., Liu, H., Yao, J.F., Davis, R.A., Li, W.K.: Self-excited threshold Poisson autoregression. J. Am. Stat. Assoc. 109, 777-787 (2014). doi:10.1080/01621459.2013.872994

Weiß, C.H.: A new class of autoregressive models for time series of binomial counts. Commun. Stat. Theory Methods 38(4), 447-460 (2009). doi:10.1080/03610920802233937

Weiß, C.H., Kim, H.Y.: Parameter estimation for binomial AR(1) models with applications in finance and industry. Stat. Pap. 54, 563-590 (2013)

Weiß, C.H., Kim, H.Y.: Diagnosing and modeling extra-binomial variation for time-dependent counts. Appl. Stoch. Models Bus. Ind. 30, 588-608 (2014). doi:10.1002/asmb.2005

Weiß, C.H., Pollett, P.K.: Binomial autoregressive processes with density-dependent thinning. J. Time Ser. Anal. 35, 115-132 (2014)

Yu, K., Zou, H., Shi, D.: Integer-valued moving average models with structural changes. Math. Problems Eng. Article ID 231592 (2014)

Zou, H., Yu, K.: First order threshold integer-valued moving average processes. Dyn. Contin. Discrete Impuls. Syst. Ser. B Appl. Algorithms 21, 197-205 (2014)

Zucchini, W., MacDonald, I.L.: Hidden Markov Models for Time Series: An Introduction Using R. Chapman \& Hall/CRC Monographs on Statistics \& Applied Probability. CRC Press, Boca Raton (2009) 